\title{
On the origin and pathway of the saline inflow to the Nordic Seas: insights from models
}

\author{
A.L. New ${ }^{\text {a, }}{ }^{*}$, S. Barnard ${ }^{\text {a }}$, P. Herrmann ${ }^{\text {b }}$, J.-M. Molines ${ }^{c}$ \\ ${ }^{a}$ Southampton Oceanography Centre, Southampton SO14 3ZH, UK \\ ${ }^{\mathrm{b}}$ Institut für Meereskunde, D-24105 Kiel, Germany \\ ${ }^{c}$ Laboratoire des Ecoulements Géophysiques et Industriel, 38041 Grenoble, France
}

\begin{abstract}
The behaviours of three high-resolution ocean circulation models of the North Atlantic, differing chiefly in their description of the vertical coordinate, are investigated in order to elucidate the routes and mechanisms by which saline water masses of southern origin provide inflows to the Nordic Seas. An existing hypothesis is that Mediterranean Overflow Water (MOW) is carried polewards in an eastern boundary undercurrent, and provides a deep source for these inflows. This study, however, provides an alternative view that the inflows are derived from shallow sources, and are comprised of water masses of western origin, carried by branches of the North Atlantic Current (NAC), and also more saline Eastern North Atlantic Water (ENAW), transported northwards from the Bay of Biscay region via a 'Shelf Edge Current' (SEC) flowing around the continental margins. In two of the models, the MOW flows northwards, but reaches only as far as the Porcupine Bank $\left(53^{\circ} \mathrm{N}\right)$. In third model, the MOW also invades the Rockall Trough (extending to $60^{\circ} \mathrm{N}$ ). However, none of the models allows the MOW to flow northwards into the Nordic Seas. Instead, they all support the hyporthesis of there being shallow pathways, and that the saline inflows to the Nordic Seas result from NAC-derived and ENAW water masses, which meet and partially mix in the Rockall Trough. Volume and salinity transports into the southern Rockall Trough via the SEC are, in the various models, between 25 and $100 \%$ of those imported by the NAC, and are also a similarly significant proportion $(20-75 \%)$ of the transports into the Nordic Seas. Moreover, the highest salinities are carried northwards by the SEC (these being between 0.13 and 0.19 psu more saline at the southern entrance to the Trough than those in the NAC-derived waters). This reveals for the first time the importance of the SEC in carrying saline water masses through the Rockall Trough and into the Nordic Seas. Furthermore, the high salinities found on density surfaces appropriate to the MOW in the Nordic Seas are shown to result from the wintertime mixing of the saline near-surface waters advected northwards by the SEC/NAC system. Throughout, we have attempted to demonstrate the extent to which the models agree or disagree with interpretations derived from observations, so that the study also contributes to an ongoing community effort to assess the realism of our current generation of ocean models. (C) 2001 Elsevier Science Ltd. All rights reserved.
\end{abstract}

\footnotetext{
* Corresponding author. Tel.: +44 (0)2380 596173; fax: +44 (0)2380 596204.

E-mail address: a.new@soc.soton.ac.uk (A.L. New).
} 


\section{Contents}

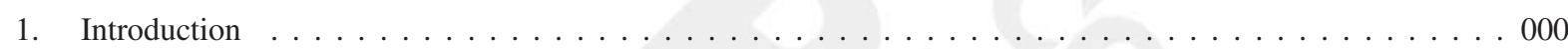

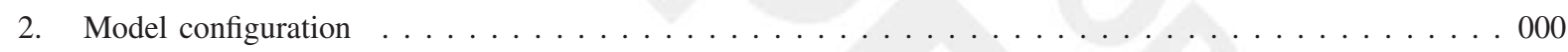

3. Poleward flow of Mediterranean Overflow Water . . . . . . . . . . . . . . 000

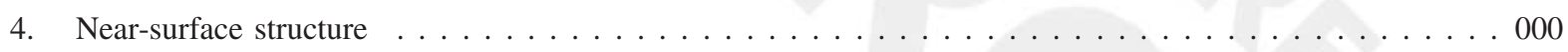

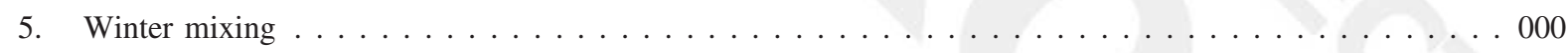

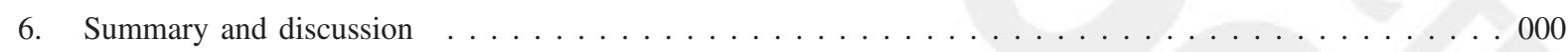

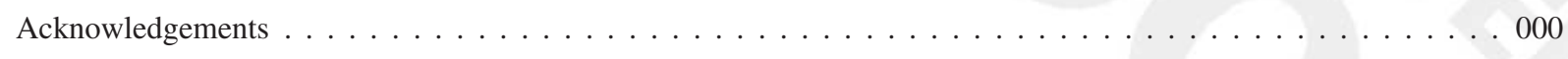

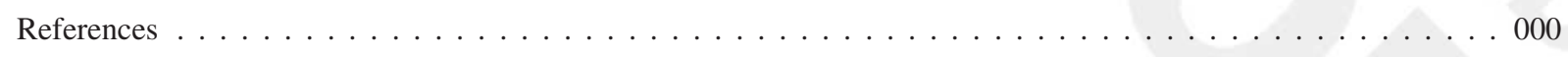

\section{Introduction}

Although waters of relatively high salinity are well known in the southern Nordic Seas, there is uncertainty as to the route by which they arrive there. There are no sources for such saline water masses in the Arctic or Nordic Seas, so they must have a southern origin. Reid (1979) proposed that Mediterranean Overflow Water (MOW) provides their source. He analysed salinity and silicate patterns in the northeast Atlantic, and although the most obvious extension of the high-salinity MOW is westward across the North Atlantic from its source in the Gulf of Cadiz, he also conjectured that it is transported in a poleward eastern boundary undercurrent around the European continental slopes. At its source, the core of the MOW was taken to coincide with a density surface at a depth near $1200 \mathrm{~m}$, and the undercurrent was proposed to carry the MOW polewards through the Bay of Biscay and the Rockall Trough. At the northern end of the Trough, this density surface rises to $400 \mathrm{~m}$ and shallower, and then passes over the Wyville-Thomson Ridge $\left(60^{\circ} \mathrm{N}\right)$, so that the MOW might eventually progress into the Nordic Seas. Once there, the high salinity water was conjectured to increase the density of the near-surface layers in the Nordic Seas, and possibly to govern the extent to which winter convection occurs there, so determining an important part of the thermohaline overturning of the entire Atlantic Ocean.

Observationally, the poleward spreading of the MOW in a reasonably steady boundary undercurrent from the Gulf of Cadiz as far as the Porcupine Seabight $\left(51-52^{\circ} \mathrm{N}\right)$ is well documented, although its progress further northward is less certain. For instance, the poleward flow of the MOW has been documented near its source in the Gulf of Cadiz by Zenk and Armi (1990), over the Portuguese slopes by Daniault, Mazé, and Arhan (1994), and at various locations between the northern Spanish slopes and the Porcupine Seabight by Pingree and Le Cann (1990). Near the Gulf of Cadiz and over the Portuguese slopes, the MOW is characterised by two cores of high salinity, centred at depths around $750 \mathrm{~m}$ and $1250 \mathrm{~m}$ respectively, but further north there is usually only a single core centred between 800 and $1200 \mathrm{~m}$ deep. Typical flow speeds are in the range $5-10 \mathrm{~cm} \mathrm{~s}^{-1}$ but can exceed $20 \mathrm{~cm} \mathrm{~s}^{-1}$ in places. 
However, McCartney and Mauritzen (2001) have reported that recent observations (from 1996) show the presence of MOW in an eastern boundary undercurrent only as far as the Porcupine Bank $\left(53^{\circ} \mathrm{N}\right)$, but no penetration of MOW further northwards into the Rockall Trough. Consequently, and on the basis of regional water mass distributions and geostrophic shear, they reject the Reid (1979) hypothesis. Furthermore, Ellett, Edwards, and Bowers (1986) observed the predominant flow pattern at depths (near $500 \mathrm{~m}$ ) just above the Wyville-Thomson Ridge to consist of Norwegian Sea Deep Water (NSDW) flowing in a southwestward direction. This water mass then rapidly sank to depths of $1200 \mathrm{~m}$, and then followed the Feni Ridge to the south. Consequently, the NSDW is at a depth, and on a density surface, comparable to those that might be occupied by the MOW in the Rockall Trough. Therefore, this southwestward flow of the NSDW over the Wyville-Thomson Ridge also argues against the northward progression of the MOW into the Nordic Seas, and against the Reid's (1979) hypothesis.

Instead of the MOW providing a deep source for the warm, saline inflows to the Nordic Seas, McCartney and Mauritzen (2001) proposed that these inflows are derived from shallower, upperocean water masses that are carried by a branch of the North Atlantic Current (NAC) flowing northwards through the Rockall Trough. This concept is supported by the observations of Pingree (1993), who used drifting buoys, drogued in the top $500 \mathrm{~m}$, to derive an upper ocean circulation pattern. His results clearly show a branch of the NAC south of the Rockall Plateau sweeping eastwards and then turning to the northeast to flow through the Rockall Trough at a mean speed of about $7 \mathrm{~cm} / \mathrm{s}$. Furthermore, Ellett et al. (1986) estimated the mean northward transport of upper layer waters (above $500 \mathrm{~m}$ ) in the central Rockall Trough (not including contributions from currents attached to the slope regions) to be $2.7 \mathrm{~Sv}$, a significant proportion of the amount required to balance the net outflows of deep waters from the Nordic Seas $(5.6 \mathrm{~Sv}$, Dickson \& Brown, 1994). The flow of NAC-derived waters through the central Rockall Trough is, therefore, likely to provide a significant part of the inflow to the Nordic Seas.

However, a complete description of the upper-layer waters in the Rockall Trough appears more complex. Ellett et al. (1986), in a circulation schematic derived from a variety of sources, show both an input of NAC waters from the southwest of the Trough (crossing $20^{\circ} \mathrm{W}$ near $50-51^{\circ} \mathrm{N}$ ), and also a more southerly input from the Bay of Biscay region (which for present purposes we generously define as the area east of $17^{\circ} \mathrm{W}$ and between 43 and $50^{\circ} \mathrm{N}$ ). One of these southerly inputs moves north along $15^{\circ} \mathrm{W}$ at $50^{\circ} \mathrm{N}$ and one circulates around the Porcupine Seabight following the shelf edge contours. (We will refer to such flows around the continental slopes as the 'Shelf Edge Current', or SEC). All three branches meet on the western Porcupine Bank, and then feed two other branches, which flow to the northeast and the north-northeast, sweeping into and filling the Trough itself. This schematic outline is supported by Bersch (1995), who presented ADCP observations along $52.5^{\circ} \mathrm{N}$. These show significant $(20 \mathrm{~cm} / \mathrm{s})$ currents to the northeast flowing between 18 and $23^{\circ} \mathrm{W}$, and indicated there is both a direct input of NAC into the Rockall Trough, and also northward flows near $15^{\circ} \mathrm{W}$ on the western side of the Porcupine Bank, indicating an input of more southerly origin.

Consequently, although this has not so far been proposed as a candidate mechanism, it seems possible that upper-layer waters from the Bay of Biscay may also be reaching the Rockall Trough and contributing a significant inflow into the Nordic Seas. In support of this, we remark that the Shelf Edge Current has been identified at several locations along the upper European continental slopes from the Iberian margins to the Norwegian Sea, taking the form of a generally poleward 
flow of warm, saline upper-layer waters in the top 400-500 m. Furthermore, Pollard, Griffiths, Cunningham, Read, Perez and Rios (1996) have identified the Biscay area as the source region for 'Eastern North Atlantic (Central) Water' (denoted by ENAW herein), a convectively formed mode water which is more saline that its counterpart 'Western North Atlantic Water' (WNAW) or the 'North Atlantic Central Water' (NACW) in general. The SEC therefore travels around the edge of the ENAW source region and, together with other northward flows through the region, which later join with the SEC (such as that near $15^{\circ} \mathrm{W}$ reported by Ellett et al., 1986), may provide a route whereby this saline water mass enters the Nordic Seas. We also note that neither Reid (1979) nor McCartney and Mauritzen (2001) were able to assess the role of the SEC in this respect, through an insufficiency of data.

An excellent review of the SEC is provided by Huthnance (1986), even so we will briefly describe some of the relevant observations. Evidence for the presence of the SEC on the Iberian slopes $\left(40-43^{\circ} \mathrm{N}\right)$ is provided by Haynes and Barton (1990), who showed that the tracks of six near-surface drifters indicated that there was a net northward flow between September 1986 and March 1987, which was associated with relatively warm surface water. Pingree and Le Cann (1990) also observed a poleward-flowing current of warm near-surface water during the winter months, which extended around the upper slope regions north of Spain and through the Bay of Biscay; a phenomenon which they termed the 'Navidad'. A mooring on the north Spanish slopes recorded eastward flows, which reached $10-15 \mathrm{~cm} / \mathrm{s}$ during the winter months, although some reversals were observed during the summer months. On the Armorican slopes $\left(46-48^{\circ} \mathrm{N}\right)$, Pingree and Le Cann (1989) recorded mean poleward speeds of $6 \mathrm{~cm} / \mathrm{s}$ near the $500 \mathrm{~m}$ depth contour, and estimated the volume transport between the shelf break and the $1000 \mathrm{~m}$ isobath at $47.5^{\circ} \mathrm{N}$ as $0.6 \mathrm{~Sv}$.

Further north, White and Bowyer (1997) revealed a poleward current carrying warm, saline (above $35.39 \mathrm{psu}$ ) water over the shelves to the west and north of Ireland, passing both over the saddle between the Porcupine Bank and the Irish shelf, and around the western slopes of the Porcupine Bank itself. To the northwest of Ireland, near $55^{\circ} \mathrm{N}$, mean flow speeds of $10-20 \mathrm{~cm} / \mathrm{s}$ were recorded in the SEC. Still further north, Huthnance (1986) reported mean speeds during the CONSLEX experiment of between 15 and $30 \mathrm{~cm} / \mathrm{s}$ at $58-59^{\circ} \mathrm{N}$, and transports of $1.2-2.2 \mathrm{~Sv}$, whereas at $60^{\circ} \mathrm{N}$ on the West Shetland slope, current speeds in excess of $30 \mathrm{~cm} / \mathrm{s}$ and transports of $4 \mathrm{~Sv}$ were observed. Thus the SEC may therefore be providing a significant proportion of the inflows required to balance the net outflows of deep waters from the Nordic Seas. Hill and Mitchelson-Jacob (1993) reported the association of the SEC on the upper continental slopes to the west of Scotland (between 56 and $59^{\circ} \mathrm{N}$ ) with a well-defined core of high salinity (reaching 35.40) near $300 \mathrm{~m}$ depth (which extended up in to the surface in the winter). The maximum salinity in this core decreased northwards, consistent with its mixing with the surrounding fresher waters. A $T-S$ analysis revealed that the properties in the core were close to those of ENAW, precluding any possibility of there being a direct Mediterranean influence. Furthermore, the continuity of the (northern portion of the) SEC has recently been convincingly demonstrated by Pingree, Sinha and Griffiths (1999), who deployed a drifting buoy (drogued at $45 \mathrm{~m}$ ) which was transported from the Irish shelf $\left(54^{\circ} \mathrm{N}\right)$ to the West Shetland shelf $\left(61^{\circ} \mathrm{N}\right)$.

As to possible mechanisms involved in driving the SEC, the JEBAR effect, as described by Huthnance (1984), is a likely candidate. This proposes a poleward oceanic density gradient and an associated sea-surface decline, with a lesser decline in shallower regions. Huthnance (1986) 
applied this theory to an idealised Hebrides Shelf case, and found poleward speeds of $12 \mathrm{~cm} / \mathrm{s}$ in a current attached to the slope. Alternatively, Holloway (1992) showed that the interaction of eddies with seafloor topography can exert large systematic forces on the ocean circulation (the 'Neptune' effect) which would tend to restore any North Atlantic circulation towards a state in which a poleward eastern boundary current would exist over the continental slopes, being particularly well defined between the Iberian slopes and the northern Rockall Trough.

Overall, although there is evidence for seasonal reversals (probably driven by changes in the wind) during the summer months on the Iberian and Spanish slopes, the SEC shows a general northward increase in both its mean (poleward) speed and transport (see also Huthnance, 1986). It is associated with a core of high salinity on the eastern slopes of the Rockall Trough and has significant transports comparable to those in the deeper Trough. It may therefore provide an important route for saline waters to reach the Nordic Seas. We also note that the circulation schematic in Ellett et al. (1986) shows the upper layer flows in the deeper Trough largely joining with those in the SEC at $58-59^{\circ} \mathrm{N}$, so that the NAC-derived waters and those originating from the Bay of Biscay may in any case become mixed together before entering the Nordic Seas.

The purpose of the present paper is to analyse three state-of-the-art, high-resolution, basin-wide ocean circulation models to examine the routes and mechanisms whereby saline water masses reach the Nordic Seas. In particular, we investigate the role of the SEC in this respect, as this has not so far been proposed as a predominant pathway. A particular strength of the present study is the investigation of three independent models. The similarities and differences between these models allow, we feel, conclusions to be drawn which are significantly more robust than those which would result from a single model alone. Furthermore, by 'confronting' the models with the available (but somewhat limited) observations, we also aim to provide insight into the abilities of the models to describe this area of complex flows. The paper is laid out in the following way: after a brief description of the models in Section 2, Section 3 investigates the poleward flow of the Mediterranean Overflow Water (MOW). Section 4 then describes the near-surface flow patterns and properties, and Section 5 examines the connections between these near-surface flows and those on the MOW density surface. Finally, the results are summarised and discussed in Section 6 .

\section{Model configuration}

The three ocean circulation models used for the present study were implemented under the 'DYNAMO (Dynamics of North Atlantic Models)' project, funded through the CEC MAST-II programme. Since detailed discussions of the configuration of the models are provided both in the final DYNAMO scientific report (DYNAMO Group, 1997), and by Willebrand et al. (2001), only brief details are given here.

The models represent the three main classes of ocean circulation model currently in widespread use, and employ different concepts for the discretisation of the vertical coordinate. They are an isopycnal-coordinate model (comprising layers of constant density referenced to the surface, $\sigma_{0}$ ) based on the MICOM code (Bleck, Rooth, Hu \& Smith, 1992), a Cartesian (or level-coordinate) model based on the GFDL-MOM code (Cox, 1984), and a sigma-coordinate (terrain-following) model based on the SPEM code (Haidvogel, Wilkin \& Young, 1991). These models will be called 
ISOPYCNIC, LEVEL and SIGMA2 respectively. ISOPYCNIC comprises a variable-density mixed layer and 19 underlying layers of constant density with values of $\sigma_{0}$ ranging between 24.70 and 28.12. On the other hand, LEVEL employs 30 fixed depth levels, and SIGMA2 uses 20 sigma-levels (constant proportions of the total depth). In these latter two models, the mixed layer depth is diagnosed as the depth at which the potential density has increased by $0.01 \mathrm{~kg} \mathrm{~m}^{-3}$ from its surface value.

As a general principle, the models were set up to be as similar as possible to each other. They use the same isotropic horizontal grid, covering the Atlantic Ocean from $19^{\circ} \mathrm{S}$ to $70^{\circ} \mathrm{N}$ at a resolution of $1 / 3^{\circ}$ longitude, and were all initialised from the (September) Levitus (1982) dataset (enhanced near the northern boundary by the merging of additional CTD data). The wind stress and heat flux used to force the models were derived from the global 6-hourly analyses performed at ECMWF and represented mean (monthly climatological) conditions between 1986 and 1988, while the surface salinity was restored towards the Levitus (1982) climatology. The monthly means of the forcing datasets were first prepared by averaging together all data within each calendar month over the three years, to produce a single dataset (of each flux) for each month. (For instance, the 'January' dataset for heat flux represented the average of the 6-hourly heat flux data over the three Januarys in 1986, 1987 and 1988.) Now, the usual practice of forcing an ocean model by linear interpolations in time of the monthly mean data (for each grid point, with the monthly mean data defined at the centres of the months) does not produce a forcing whose mean over a month is the data value required. Consequently, we adopted the algorithm developed by Killworth (1996) to avoid this difficulty. Essentially, the datasets are adjusted through a matrix algorithm to ensure the model receives the correct monthly mean values. Failure to adopt this methodology can lead to large errors in the applied fluxes (as much as $10 \%$ in the wind stress example studied by Killworth, 1996), with correspondingly important implications for the modelled circulation, the response of which to the applied fluxes is likely to be highly nonlinear.

The models were each integrated for a period of 20 years, and the last 5 years were averaged to produce mean seasonal climatologies (with winter, for instance, including January, February, and March, and likewise for the other seasons). All output datasets for comparison purposes in the present study were interpolated onto a Cartesian (A-) grid, constructed from the models' horizontal grid (for mass points) together with 61 levels in the vertical.

Relaxation zones (to simulate water mass exchanges with basins outside the model domain) were employed near the northern and southern boundaries of the models, and near Gibraltar, at which temperature and salinity (layer depth and salinity for the ocean interior in ISOPYCNIC) were relaxed to climatological conditions. As there is a relevance for the present study, and as a specific example, we remark that the relaxation timescale was 14 days at the Strait of Gibraltar $\left(36^{\circ} \mathrm{N}, 6^{\circ} \mathrm{W}\right)$, and increased linearly to 100 days at a radius of $300 \mathrm{~km}$. The relaxation zone extended out to $11^{\circ} \mathrm{W}$, and to $33.5^{\circ} \mathrm{N}$ and $38^{\circ} \mathrm{N}$, and only the upper $2500 \mathrm{~m}$ of the water column (or down to the interface between the layers of densities 27.82 and 27.88 for ISOPYCNIC) was relaxed in this way, to cover the expected depth range of the Mediterranean outflow water masses. (An error was discovered in the implementation of this relaxation zone for the original run of the SIGMA model, but this was corrected in a second model run called SIGMA2, which also had steeper, more realistic bathymetry, and which we use for the present investigation. See Willebrand et al., 2001, for more details.)

Finally, the topographies (and coastlines) for all the models were derived from the ETOPO5 
( $5^{\prime}$ resolution) database. For ISOPYCNIC, the ocean depth was taken as the median of all bathymetric data within each grid cell, without additional smoothing. For LEVEL, slight additional smoothing was employed to remove variations at the grid scale (and the gridpoint depth values were also taken as the nearest depth level in the model). However, somewhat stronger smoothing was needed for SIGMA2 in order to counter possible systematic errors arising from the calculation of the pressure gradient term over steep topography. The minimum ocean depth was set to $75 \mathrm{~m}$ in ISOPYCNIC, to $72 \mathrm{~m}$ in LEVEL (the nearest grid cell depth), and to $200 \mathrm{~m}$ in SIGMA2 (to limit the constraint on the time-step introduced by the convergence of the sigma-surfaces in shallow areas). Furthermore, in LEVEL and SIGMA2 the topography in certain key passages was widened in order to allow for advective transports down to the original sill depths.

The model topographies for the portion of the north-east Atlantic of primary interest to the present study are shown in Fig. 1, though we stress again the basin-wide coverage of the models. For ISOPYCNIC, Fig. 1a, the continental slopes are realistically steep, and the relevant seamounts are clear (e.g. Anton Dohrn at $57.5^{\circ} \mathrm{N}, 11^{\circ} \mathrm{W}$ and Rosemary Bank at $59.5^{\circ} \mathrm{N}, 10^{\circ} \mathrm{W}$ ). The Rockall Trough (RT in Fig. 1a) is the relatively deep area covering $54-60^{\circ} \mathrm{N}$ (shoaling from about 3000 to $2000 \mathrm{~m}$ deep) between the Irish-Scottish slopes and the Rockall Bank (marked as R in Fig. $1 \mathrm{a}$, and which rises nearest the surface at $57.5^{\circ} \mathrm{N}, 13.5^{\circ} \mathrm{W}$ ). The Wyville-Thomson Ridge (W) forms a rise at the northern end of the Trough $\left(60-61^{\circ} \mathrm{N}, 6-9^{\circ} \mathrm{W}\right)$ with depths in the range 600 $800 \mathrm{~m}$, while further to the northeast the Faeroe-Shetland Channel (F) forms a deepening pathway into the Nordic Seas (between 60 and $63^{\circ} \mathrm{N}, 6-0^{\circ} \mathrm{W}$ ). Further to the south, other important topographic features are the Porcupine Bank $\left(\mathrm{P}\right.$, shallowest near $\left.53.5^{\circ} \mathrm{N}, 14^{\circ} \mathrm{W}\right)$ and the Goban Spur $\left(\mathrm{G}, 49.5^{\circ} \mathrm{N}, 11^{\circ} \mathrm{W}\right)$. For LEVEL, Fig. $1 \mathrm{~b}$, the effect of the additional processing is evidenced by the slightly broader continental slopes and deeper seamounts. For SIGMA2 (Fig. 1c), the necessary smoothing results in a continuation of this trend, and continental slopes are typically twice as broad as for ISOPYCNIC. However, even in SIGMA2, all the major topographic features are adequately represented.

\section{Poleward flow of Mediterranean Overflow Water}

We begin our investigation by studying the flow characteristics on a density surface appropriate to Mediterranean Overflow Water (MOW). Reid (1979) took this as the $27.69\left(\sigma_{0}\right)$ surface above $500 \mathrm{~m}$ depth, and its extension onto a matching surface $\left(\sigma_{1}=32.274\right)$ below $500 \mathrm{~m}$, to capture the MOW core properties near its origin in the Gulf of Cadiz. However, more recent observations (McCartney \& Mauritzen, 2001) show the core of the MOW coinciding more closely with the $27.60\left(\sigma_{0}\right)$ surface near the Goban Spur (G in Fig. 1a, entering our region of primary interest), so we choose this surface for the present study. We also remark that fluid parcels in the ocean interior would be expected to move approximately on constant density surfaces, so that flow quantities (such as salinity) on density surfaces act as useful tracers for diagnosis of the circulation patterns.

Fig. 2 examines the salinity on the 27.60 density surface, and Fig. 2a presents the situation for the Levitus (1982) dataset (in September). This was used as the initial condition of the models, and so enables an assessment of how the model circulation has altered this state. It is also a useful observational dataset for comparison with the model results. This surface is in the depth 
(a)

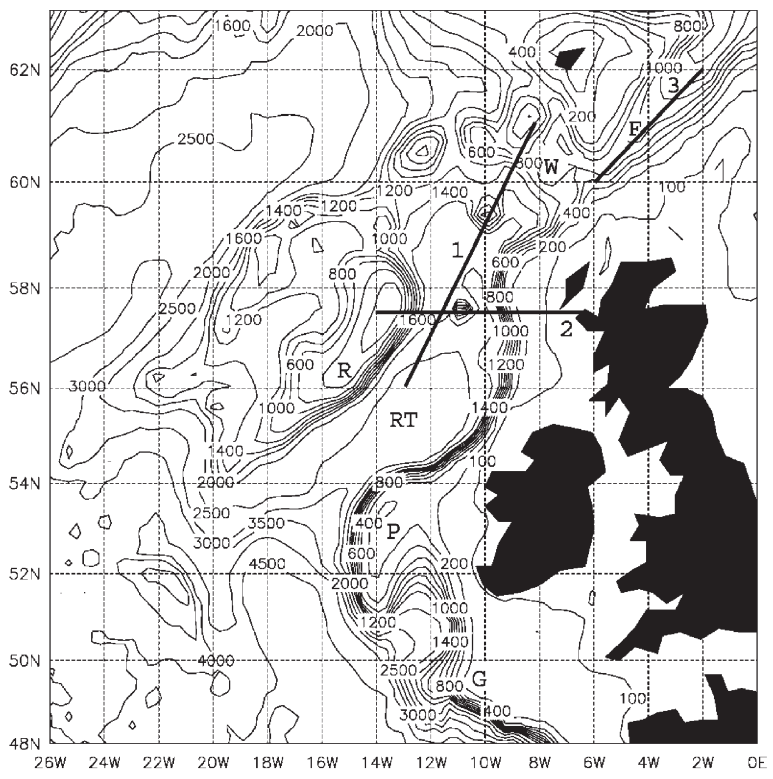

(b) LEVEL: Topography (m)

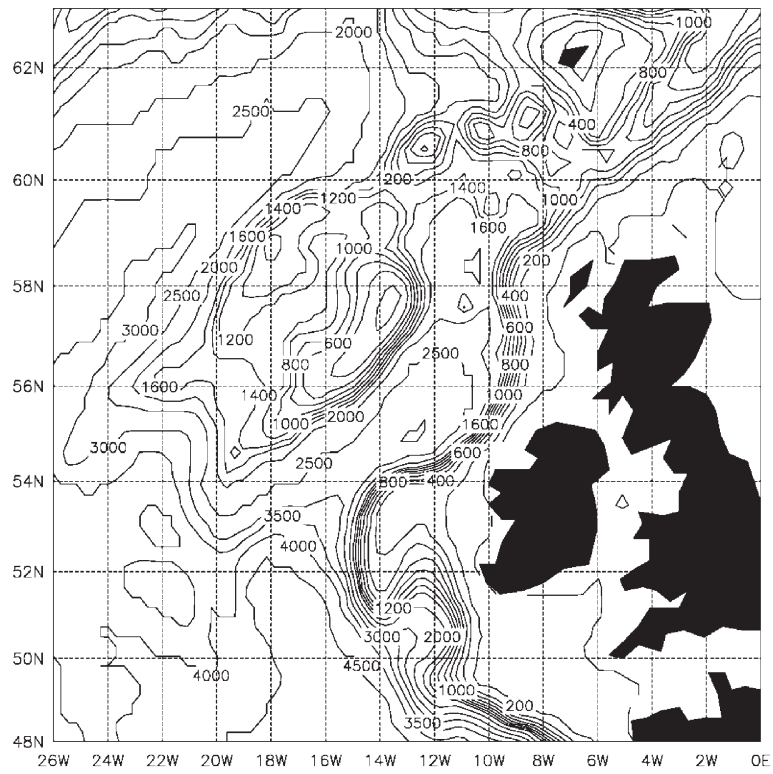

(c) SIGMA2: Topography (m)

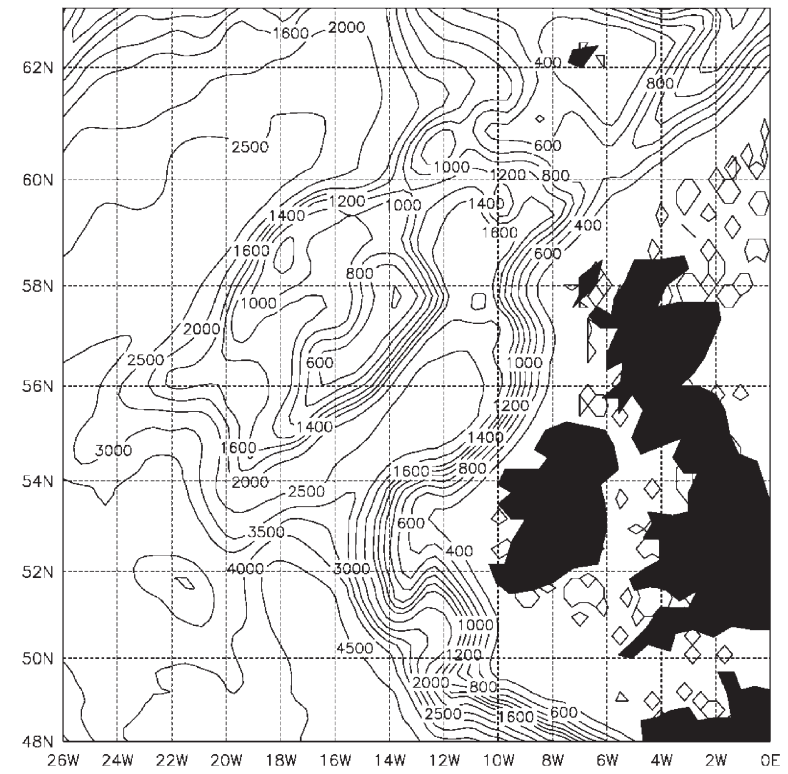

Fig. 1. Model topographies (m) in the northeast Atlantic sub-domain for (a) ISOPYCNIC, (b) LEVEL and (c) SIGMA2. Contours are at 100, 200, 400, 600, 800, 1000, 1200, 1400, 1600, 1800 and $2000 \mathrm{~m}$, and subsequently at $500 \mathrm{~m}$ intervals. Marked in part (a) are the Goban Spur $(\mathrm{G})$, the Porcupine Bank (P), the Rockall Trough (RT), the Rockall Bank (R), the Wyville-Thomson Ridge (W), the Faeroe-Shetland Channel (F) and sections 1 (corresponding to Fig. 5), 2 (Fig. 9) and 3 (Fig. 10). 
range 900-1000 m between the Gulf of Cadiz, around the European margins and into the Rockall Trough (RT in Fig. 1a), but rises over the Wyville-Thomson Ridge (WTR, see W in Fig. 1a), reaching depths of 200-400 $\mathrm{m}$ in the Faeroe-Shetland Channel (FSC, see F in Fig. 1a) and southern Nordic Seas (not shown). The highest salinities of $>36.00$ are present off the Portuguese slopes, representing the MOW near its source. We infer spreading of the MOW to the north (and also to the west), as evidenced by the decreasing salinities, but only (northwards) as far as the Porcupine Bank $\left(54-55^{\circ} \mathrm{N}\right.$, see P in Fig. 1a), where a minimum of salinity of around 35.15 occurs. Further north, salinities again increase, with a maximum of 35.30 occurring near the WTR, but they are also relatively high $(>35.25)$ in the FSC and southern Nordic Seas.

The continuous spreading of MOW into the Nordic Seas (as postulated by Reid, 1979) would be expected to be reflected by a steady decrease in salinity with advection distance to the north, with the MOW properties becoming gradually more dilute through mixing with the fresher waters on this surface in the wider North Atlantic. The presence of the salinity minimum near $55^{\circ} \mathrm{N}$, together with the increasing salinities further north, therefore count against this possibility. Instead, these factors indicate that there is an import of fresher waters from the west into the southern Rockall Trough, and that there is possibily a different source for the higher salinity waters further to the north. A similar salinity minimum is also seen in the recent isopycnally-averaged dataset of Lozier, Owens, and Curry (1995) along a nearby density surface $\left(\sigma_{0}=32.35\right)$, again supporting these conclusions. (Furthermore, Pollard et al. (1996) revealed an anomalously fresh water mass in the upper ocean near $53^{\circ} \mathrm{N}, 16^{\circ} \mathrm{W}$ which may additionally indicate a branch of the North Atlantic Current here.) However, the datasets of Levitus (1982) and Lozier et al. (1995) do not resolve fine-scale boundary currents, so the apparent presence of the salinity minimum on the northern Porcupine Bank does not necessarily preclude the possibility of MOW being transported northwards in a thin, inshore boundary current, as conjectured by Reid (1979), but neither do they offer any support for such a postulate.

The 27.60 density surface in the Rockall Trough occurs at depths of between 1100-1300 m in ISOPYCNIC, and 800-1100 $\mathrm{m}$ in LEVEL and SIGMA2, and in all models it rises to depths of $100-400 \mathrm{~m}$ to the north of the WTR (see Figs. 5 and 10). Figs. $2 \mathrm{~b}$ and $2 \mathrm{c}$ illustrate the salinity on this surface for ISOPYCNIC and LEVEL in fall (soon after the Levitus initialisation field), and the general pattern is qualitatively the same as in the Levitus observations. In both models, there is still a maximum salinity off the Portuguese slopes, though the maximum values have decreased to 35.75 and 35.70 respectively, and there is evidence of both westward and northward spreading. Furthermore, there is a salinity minimum in both models to the west of the Porcupine Bank, with salinity increasing further to the north (with highest values of 35.35 near the WTR, in close agreement with the observations). For ISOPYCNIC, the minimum is about 35.2 at $54^{\circ} \mathrm{N}$ and appears to be caused by a branch of fresher water from the west (confirmed below). For LEVEL, the region of lowest salinity (about 35.25) occupies a larger meridional extent. These patterns indicate a poleward spreading of the MOW that does not extend beyond the Porcupine Bank. For SIGMA2, however, the situation is different (Fig. 2d). Again, the MOW exhibits both westward and northward spreading with gradual decrease in salinities. The northward spread,

Fig. 2. Salinity on the 27.60 isopycnal for (a) the Levitus (1982) September dataset (with darker greys for salinity above 35.22), and in fall for (b) ISOPYCNIC (darker greys for salinity above 35.25), (c) LEVEL (darker greys for salinity above 35.35 ) and (d) SIGMA2 (darker greys for salinity above 35.30 ). 
(a) LEVITUS: Salinity (psu) on 27.60

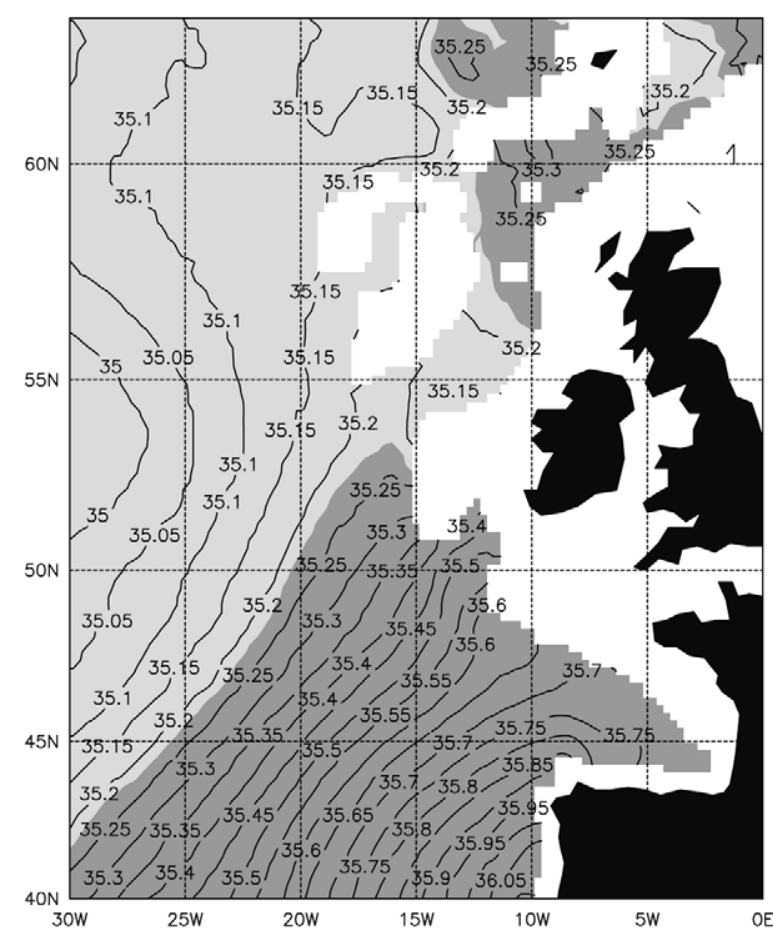

(c) LEVEL: Fall Salinity (psu) on 27.60

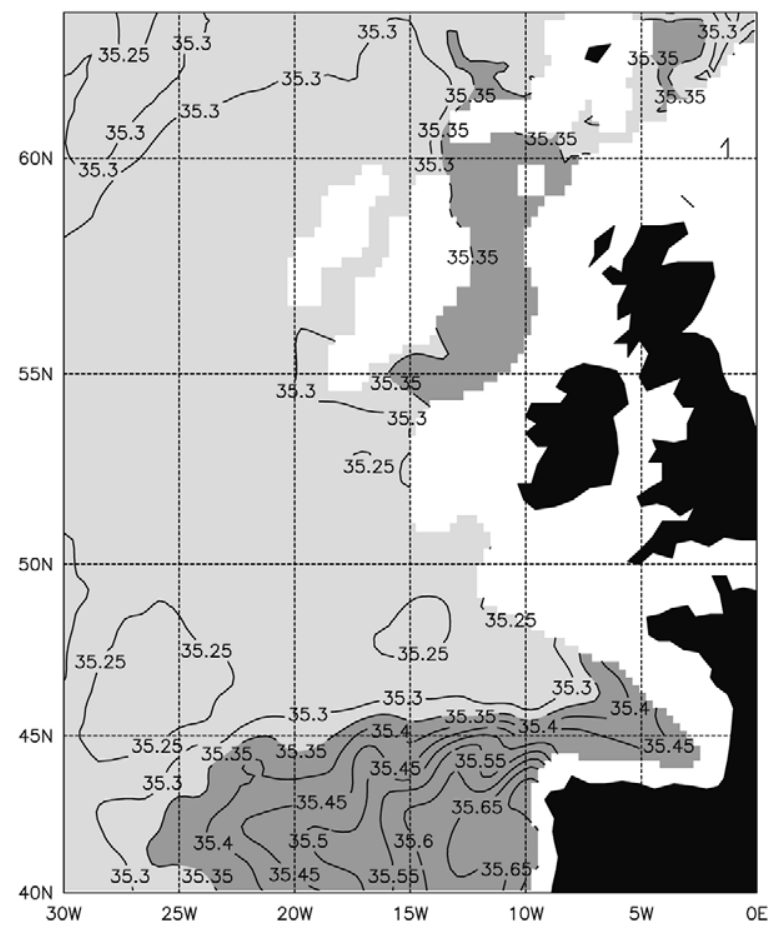

(b) ISOPYCNIC: Fall Salinity (psu) on 27.60

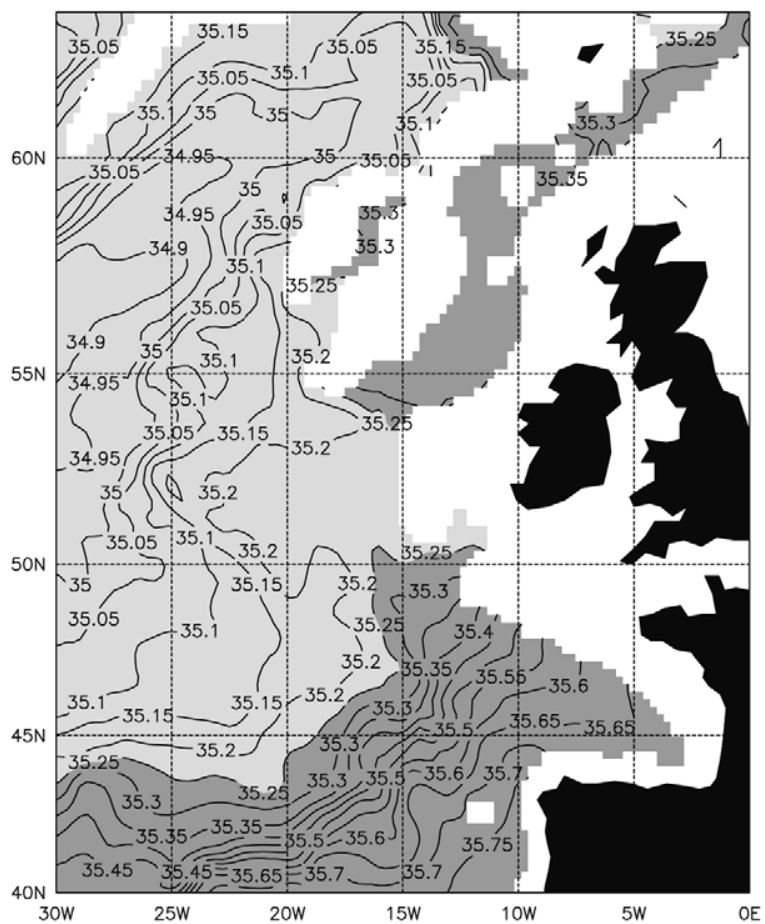

(d) SIGMA2: Fall Salinity (psu) on 27.60

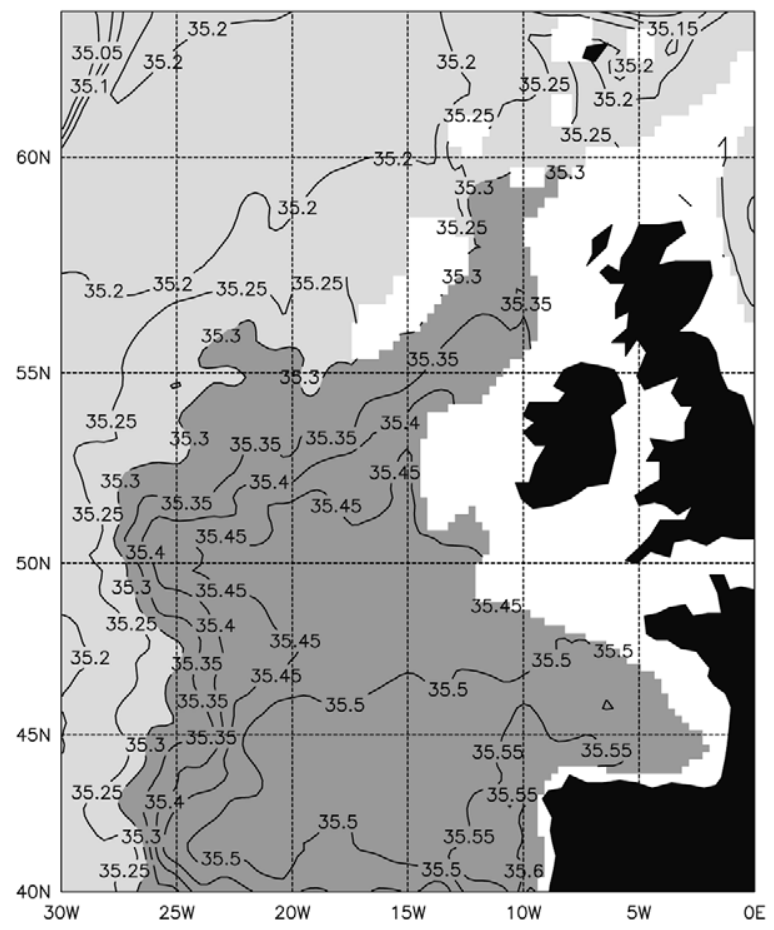


however, in this case occurs in a broad region between the continental slopes and $20-25^{\circ} \mathrm{W}$ and reaches about $52^{\circ} \mathrm{N}$, where it then enters the Rockall Trough in an eastern boundary undercurrent (carrying the highest salinities). There is no salinity minimum in this region of the model, and it is clear that the MOW spreads to fill the entire Rockall Trough (see also Fig. 5c).

Figs. 3 and 4 show the flow patterns on the 27.60 surface in the fall (which also happens to be the time of year when ISOPYCNIC and LEVEL have their strongest poleward undercurrent, giving the best opportunity for MOW to invade the Rockall Trough). Fig. 3a shows that there is a well-defined poleward boundary undercurrent in ISOPYCNIC extending from the Portuguese slopes, around the Bay of Biscay, and as far as the western Porcupine Bank $\left(52-53^{\circ} \mathrm{N}\right)$. As it travels northwards, water is expelled from the undercurrent at both $47.5^{\circ} \mathrm{N}$ and at the Goban Spur $\left(49.5^{\circ} \mathrm{N}\right)$. This expelled water reforms and largely flows to the southwest along the Azores-Biscay rise. As a consequence, the undercurrent is much weakened by the time it reaches $52^{\circ} \mathrm{N}$. The path of the undercurrent further to the north is then blocked by two large eddies (a cycloneanticyclone pair) in the southern Rockall Trough. These do not allow much possibility of MOW invading the Trough, although some may be taken up into the southernmost of the eddies and expelled westwards near $53^{\circ} \mathrm{N}$. The eddies are quasi-stationary through the year and appear to be topographically controlled. The anticyclone is fed by a branch of water from the west along 53$54^{\circ} \mathrm{N}$, which originates in the North Atlantic Current (the main pathway for which passes through the north-western corner of the figure). This is the source of the fresher water, and the salinity minimum seen in Fig. 2b. Further to the north, the main body of the Rockall Trough is fed from a northern source, with a current to the south down the western slopes of the Trough (following the Feni Ridge), which turns eastwards near $54^{\circ} \mathrm{N}$ and then recirculates to the north in the central and eastern Trough. Consequently in ISOPYCNIC, the Porcupine Bank is effectively the northern limit to the spread of MOW, and this is where fresher water is introduced from the west. Further to the north, there is a different flow regime, with a likely northern source. This is entirely consistent with, and supports the inferences drawn from, the salinity patterns in Fig. $2 b$.

In LEVEL, Fig. 3b, the situation is broadly similar. The poleward undercurrent again extends from the Portuguese slopes, around the Bay of Biscay, and as far as the western Porcupine Bank. There it encounters a complex flow pattern, which is dominated by a series of large, quasistationary eddies. Water in the undercurrent is partly ejected off the Porcupine Bank near $52^{\circ} \mathrm{N}$, and partly swept into the southern Rockall Trough, but only for most of it to be ejected again near $54^{\circ} \mathrm{N}$. As for ISOPYCNIC, eddies effectively block the further northward progression of the MOW. We also note that flows of water are moving in from the west, bringing fresher NACderived waters to the region. These affect the eastern boundary primarily near $52-53^{\circ} \mathrm{N}$ and $48-$ $49^{\circ} \mathrm{N}$, and result in the formation of a broad region of low salinity, with minima near these latitudes (Fig. 2c). Again, the region of the central Rockall Trough, north of $54-55^{\circ} \mathrm{N}$, is fed by a current from the north, which circulates cyclonically, as occurred in ISOPYCNIC. This is associated with the region of higher salinity in the north of the Trough (Fig. 2c), which extends sothwards to $54-55^{\circ} \mathrm{N}$. We also note that the mixing of these more saline waters from the north with the fresher waters imported from the NAC can be clearly seen in Fig. 2c in the eddy centred at $55^{\circ} \mathrm{N}, 14.5^{\circ} \mathrm{W}$.

Fig. 3c reveals a qualitatively different situation for SIGMA2, which is, however, consistent with the salinity structure in Fig. 2d. The eastern boundary undercurrent runs strongly (note the change of scale) around the European margins with some expulsion of water into the Bay of 
(a)

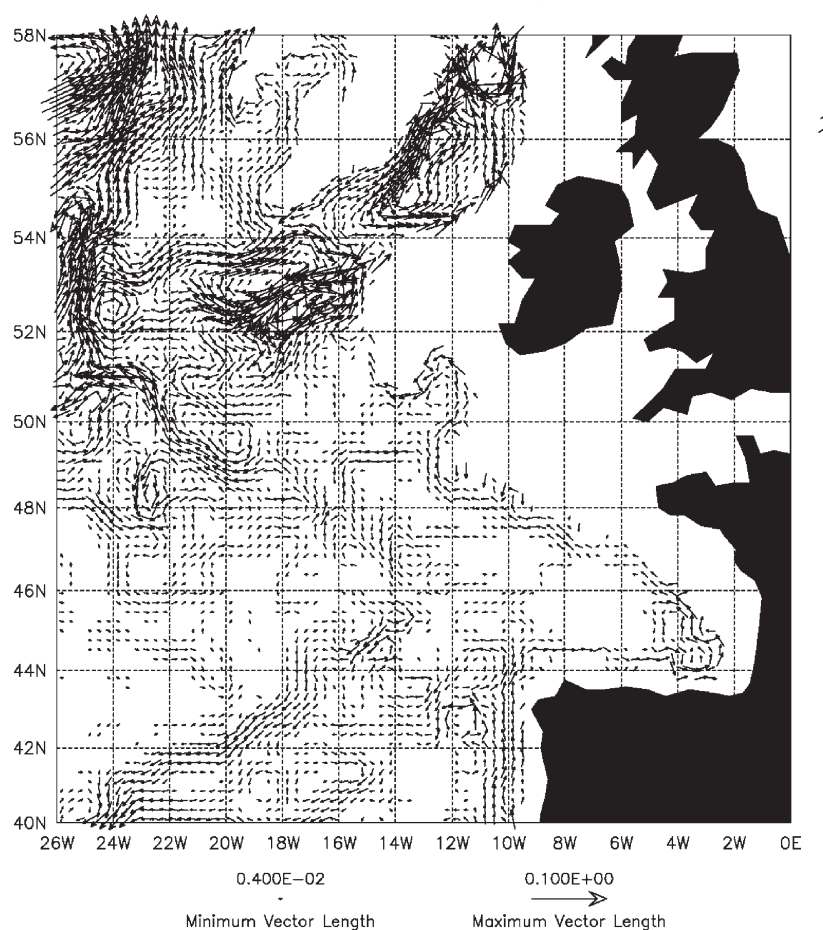

(c)

SIGMA2: Fall Currents $(\mathrm{m} / \mathrm{s})$ on 27.60

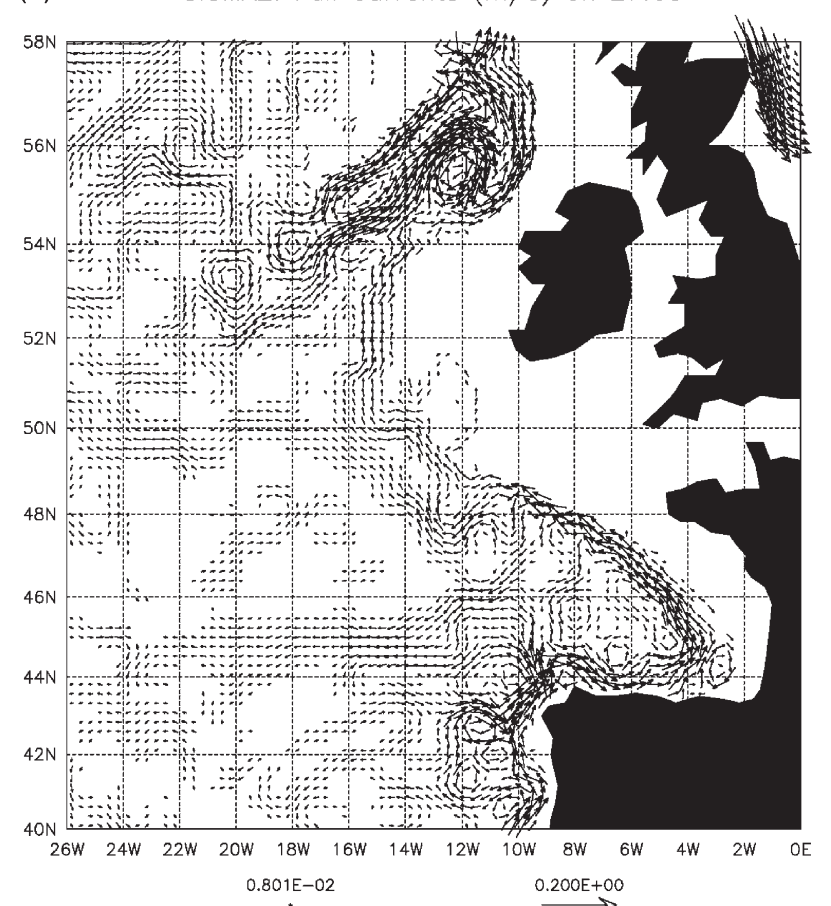

Minimum Vector Length (b) LEVEL: Fall Currents $(\mathrm{m} / \mathrm{s})$ on 27.60

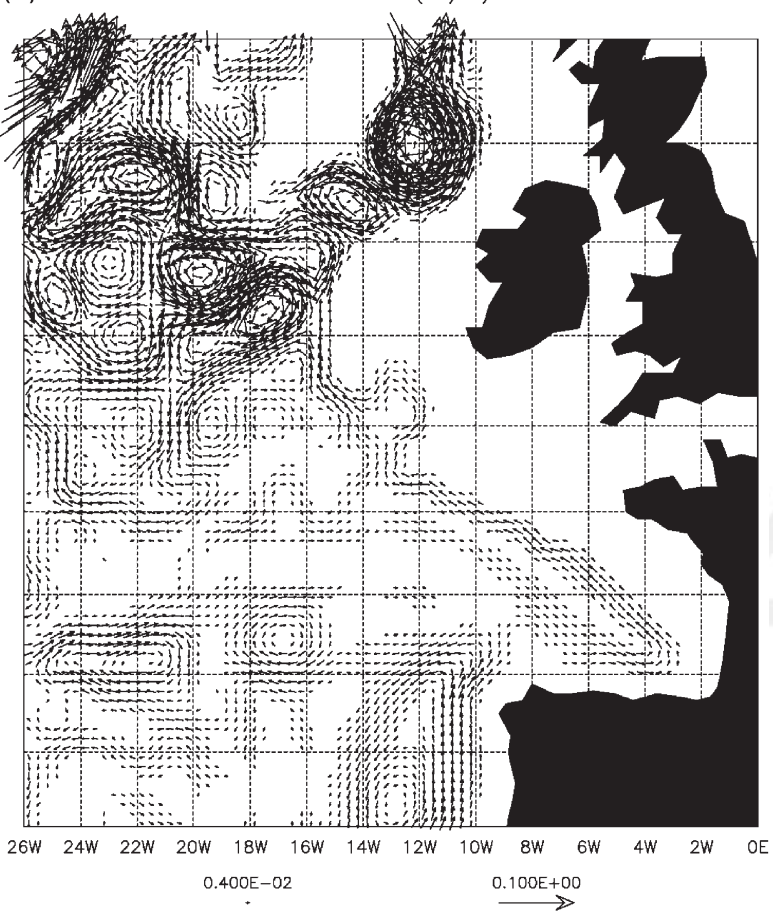

Minimum Vector Length 
Biscay $\left(46-48^{\circ} \mathrm{N}\right)$. But it clearly invades the Rockall Trough, carrying salinities of 35.45 past the western Porcupine Bank. In the central region of the Trough, the undercurrent water mixes with somewhat fresher (35.30-35.35) water coming from the west in a large eddy (centred at $55.5^{\circ} \mathrm{N}$, $12^{\circ} \mathrm{W}$ ), before it continues to sweep around and fill most of the Trough. SIGMA2 clearly indicates the presence of the MOW in the Rockall Trough.

Fig. 4 investigates the flow patterns (again in the fall) on the 27.60 density surface a little further north, near the Wyville-Thomson Ridge (WTR). In ISOPYCNIC, Fig. 4a, the flow over the ridge (which exhibits only a little seasonal variability) is strongly to the west and southwest. as the density surface descends from about $400 \mathrm{~m}$ north of the ridge to $1200 \mathrm{~m}$ on its southern flank (see Figs. 5 and 10). The overflow water then flows either side of Rosemary Bank and fills the northern portion of the Trough. Part of the water masses in the northern Trough then escapes between George Bligh Bank and Lousy Bank (at $59.5^{\circ} \mathrm{N}, 13^{\circ} \mathrm{W}$ ), and the other part recirculates around Anton Dohrn Seamount $\left(57.5^{\circ} \mathrm{N}, 11^{\circ} \mathrm{W}\right)$ before feeding the southward flow into the central Trough already noted in Fig. 3a. The waters overflowing the WTR are, therefore, involved in supplying the higher salinities to this area in Fig. 2b (investigated further below). Note also that to the north of the WTR there is a marked northeastward flow along the eastern side of the Faeroe-Shetland Channel (FSC), which is fed by currents from further to the north recirculating around the Faeroe plateau. (We also note that the locally large currents in the WTR overflow are associated with the squeezing together of neighbouring density surfaces as they rapidly descend into the Rockall Trough, much as in a weir flow, giving an apparent non-conservation of the flow on this density surface).

The situation for LEVEL is much the same, Fig. 4b. There is a strong westward and southwestward flow over the WTR. A component of the overflow waters in the northern Rockall Trough escapes between George Bligh Bank and Lousy Bank, and another feeds the circulation into the northern Rockall Trough, where they are connected with the supply of higher salinity waters to this area. North of the ridge, the flow on the eastern side of the FSC is to the northeast, as for ISOPYCNIC. For SIGMA2 (Fig. 4c) the circulation is also strongly (note the change of scale) westwards over the WTR. Most of this overflow then escapes between Lousy Bank and Bill Bailey's Bank $\left(60.5^{\circ} \mathrm{N}, 10-11^{\circ} \mathrm{W}\right)$, unlike the situation in the other two models (probably because in this model the density surface is slightly higher in the water column). However, there is also a route for some overflow water to move southwards down the western side of the northern Trough to about $58^{\circ} \mathrm{N}$, and this is associated with the fresher waters in this area in Fig. 2d. For SIGMA2, it is apparent that the WTR overflow waters (on this density surface) are fresher than the MOW waters in the northern Rockall Trough, but that mixing between these two is likely in this region. Again, note that north of the WTR the flow on the eastern side of the FSC is to the northeast (with some meanders).

Overall, all three models agree that the flow of water on this density surface is to the west or southwest over the Wyville-Thomson Ridge. Moreover, this flow pattern persists throughout the seasonal cycle, with little variation. This implies that no water mass (i.e. in particular the MOW in SIGMA2) is able to move polewards along this density surface from the Rockall Trough, over

Fig. 3. Fall currents $(\mathrm{m} / \mathrm{s})$ in the Bay of Biscay and the southern Rockall Trough, on the 27.60 isopycnal, in (a) ISOPYCNIC, (b) LEVEL and (c) SIGMA2. Note the increased speed denoted by the scale arrow for SIGMA2. Vector arrows show the velocities at the arrow centres. 
(a)

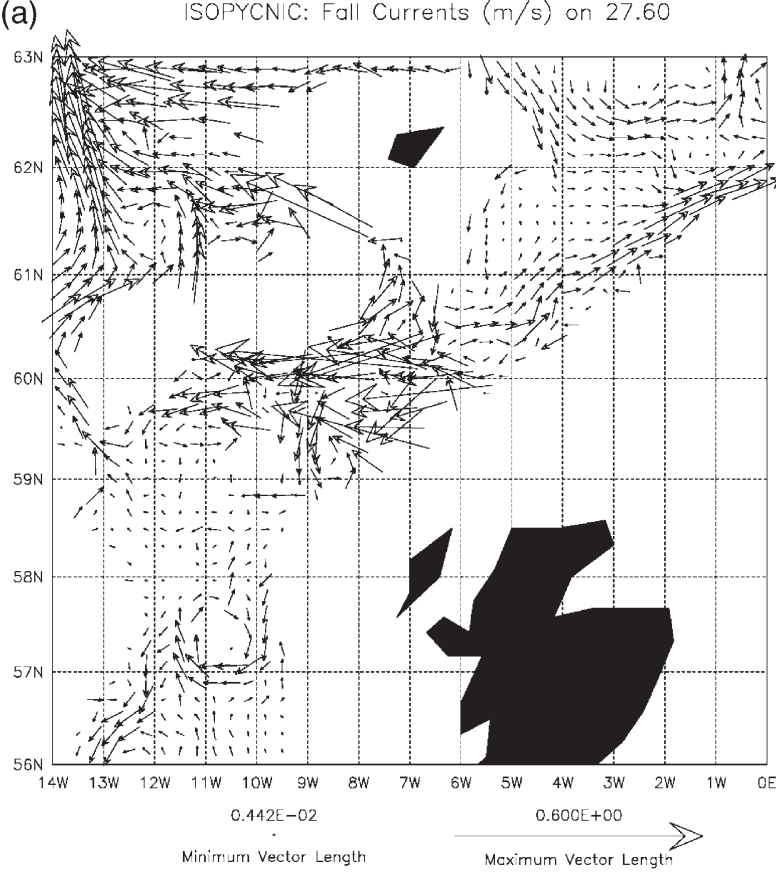

(c)

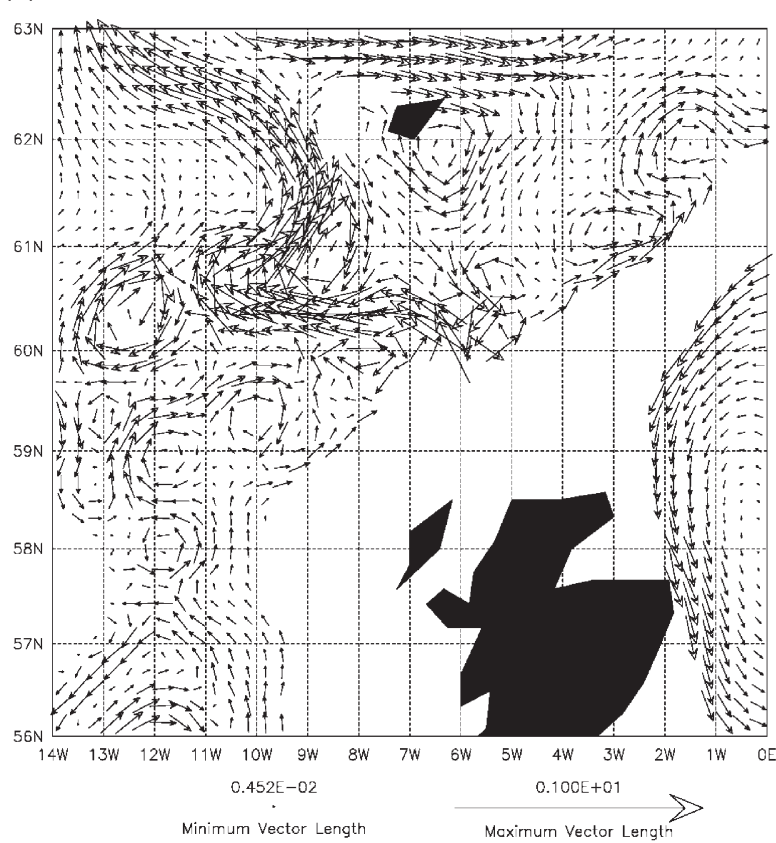

(b)

LEVEL: Fall Currents $(\mathrm{m} / \mathrm{s})$ on 27.60

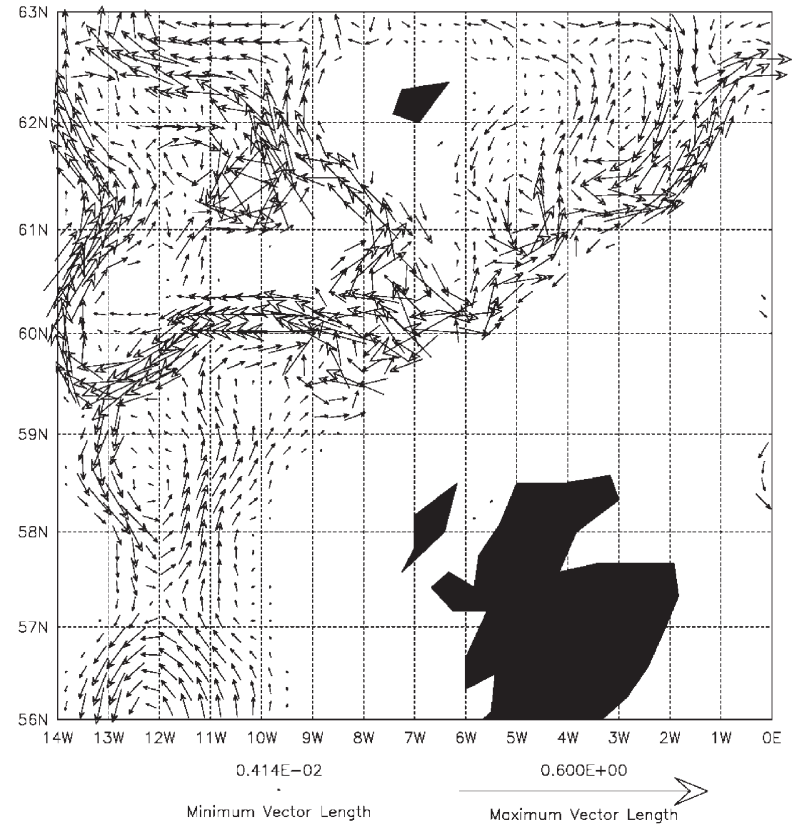

Fig. 4. Fall currents $(\mathrm{m} / \mathrm{s})$ in the northern Rockall Trough, over the Wyville-Thomson Ridge and in the FaeroeShetland Channel, on the 27.60 isopycnal, in (a) ISOPYCNIC, (b) LEVEL and (c) SIGMA2. Note the increased speed denoted by the scale arrow for SIGMA2. Vector arrows show the velocities at the arrow centres. 
(a) ISOPYCNIC: R. Trough Fall Salinity (13.0-8.3W)

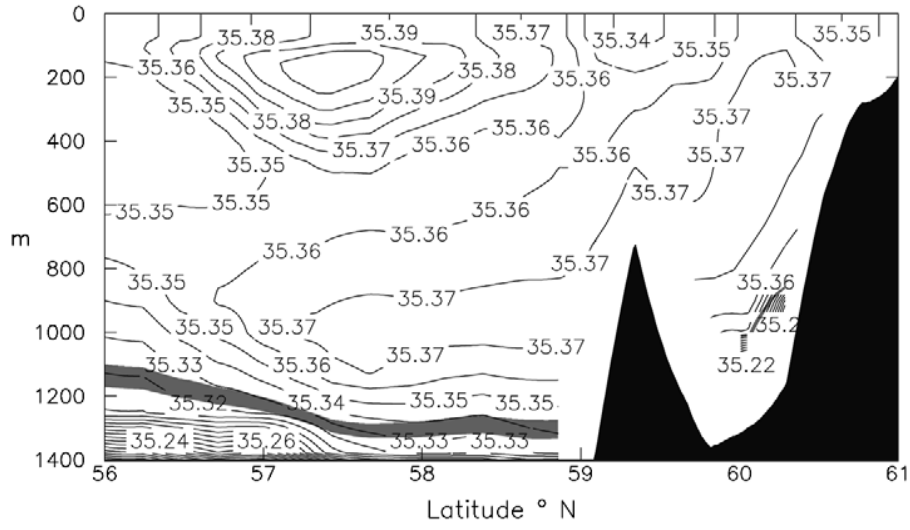

(b) LEVEL: R. Trough Fall Salinity $(13.0-8.3 \mathrm{~W})$

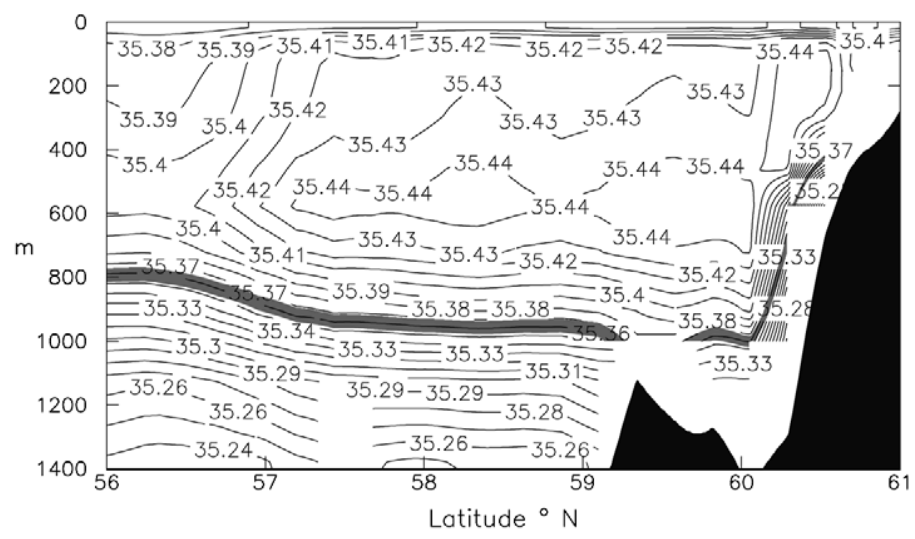

(c) SIGMA2: R. Trough Fall Salinity $(13.0-8.3 W)$

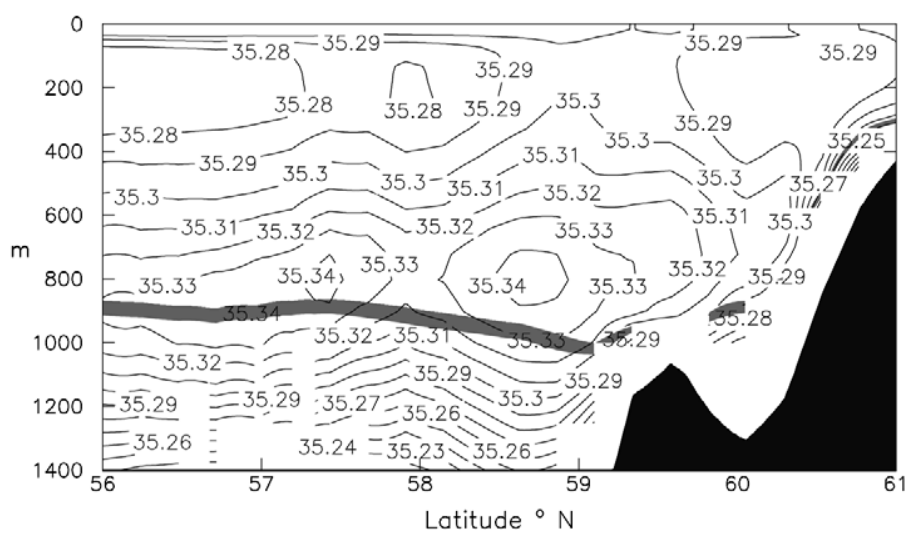

Fig. 5. Sections in fall in the Rockall Trough between $56^{\circ} \mathrm{N}, 13^{\circ} \mathrm{W}$ and $61^{\circ} \mathrm{N}, 8.3^{\circ} \mathrm{W}$ (section 1 in Fig. 1 (a)) showing salinity (contours) and the 27.60 density surface (grey shading) for (a) ISOPYCNIC (grey shading between densities of 27.592 and 27.608), (b) LEVEL (grey shading between densities of 27.585 and 27.615) and (c) SIGMA2 (grey shading between densities of 27.590 and 27.610). The vertical axis shows depth in $\mathrm{m}$. 
the WTR, and into the Nordic Seas. The models are unanimous in this respect, and so we view this as a robust result, which is counter to Reid's (1979) hypothesis, but which is in accord with the views of Ellett et al. (1986).

To summarise and further illustrate the differences between the models in this area, Fig. 5 presents sections in fall running through the Rockall Trough and up to the western WTR (section 1 in Fig. 1a). These show salinity (contours) and the depth of the 27.60 surface (grey shading). For ISOPYCNIC, the 27.60 surface is situated near $1200 \mathrm{~m}$ in the central Trough, but rises towards the WTR. This surface is located in a halocline that separates deeper fresher waters from more saline waters higher in the water column. The deeper fresher waters are seen sweeping over the WTR, flowing between the western WTR and Rosemary Bank in this section near $60^{\circ} \mathrm{N}$, before descending further and continuing on into the central Trough. These waters are the model Norwegian Sea Deep Water (NSDW), and are as fresh as 35.22 at $60^{\circ} \mathrm{N}$. At intermediate depths in the Rockall Trough there is a tongue of more saline water. This has a core salinity in excess of 35.37 and descends from near the surface at $60-61^{\circ} \mathrm{N}$ to about $1000 \mathrm{~m}$ in the central Trough, following just above the 27.60 surface (i.e. the core is on a slightly lighter density surface). This is water that is of the same salinity as the winter mixed layer above the WTR, and has been detrained by wintertime mixing (as we shall see below for the 27.60 surface). For LEVEL, Fig. $5 \mathrm{~b}$ the situation is qualitatively similar. The 27.60 surface is again situated in a halocline, but both the density surface and the halocline are higher in the water column than for ISOPYCNIC. The freshest waters in the WTR overflow are now 35.26, and the core of the higher salinity tongue at intermediate depths (which again descends southwards following a density surface slightly lighter than 27.60) now reaches 35.44. As for ISOPYCNIC, this is the same salinity as in the winter mixed layer over the WTR (see below) and this water mass has also been formed by detrainment from the winter mixed layer. For SIGMA2, Fig. 5c, the situation is different. There is again a salinity maximum at intermediate depths (near $800 \mathrm{~m}$ ), but this is clearly the MOW extending from the south up to the WTR, and does not come from a near-surface source over the WTR, as for the other models (although there is a shallow tongue with salinity near 35.29 here, which is likely to have been so formed). Also note that the 27.60 surface in this model is located close to, and just below, the intermediate salinity maximum associated with the MOW, and furthermore that the NSDW overflow waters are as fresh as 35.27.

\section{Near-surface structure}

In order to explain the occurrence of high salinity (in ISOPYCNIC and LEVEL at least) in the WTR region and the southern Nordic Seas on the 27.60 surface, and having ruled out MOW as being the primary source, we now investigate the near-surface structure. Hill and MitchelsonJacob (1993) report that although in summer, the SEC over the slopes of Malin (near $58^{\circ} \mathrm{N}$ ) is capped by summer stratification and has a subsurface core (near $300 \mathrm{~m}$ deep), in the winter this feature extends up to the surface. Since winter is also the time of year when near-surface properties affect the ocean interior via mixing, we now present the (near-) surface currents and salinity patterns in the winter. These are taken from the $53 \mathrm{~m}$ depth level (one of the depths used in the interpolation of the model output datasets to a standard set of levels for comparison purposes), in order to effectively remove the effect of the wind-driven Ekman transport, while still being 
shallow enough to reveal the structure on the shelf. We also remark that the currents at other times of year are similar to those in the winter (save for some reversals of the slope flows around Spain and the Bay of Biscay in the summer) so that the winter currents are reasonably typical of the mean patterns.

Fig. 6a shows the current structure for ISOPYCNIC. The SEC travels polewards around the Spanish slopes and through the Bay of Biscay. There is also a poleward flow over deeper water at $14^{\circ} \mathrm{W}$ (and $42-44^{\circ} \mathrm{N}$ ) which turns northeastwards into the Bay of Biscay, and further current branches impacting from the west between $46-50^{\circ} \mathrm{N}$ which join together (near $47^{\circ} \mathrm{N}, 12-14^{\circ} \mathrm{W}$ ) before turning north and augmenting the SEC at the Goban Spur $\left(49^{\circ} \mathrm{N}, 10-12^{\circ} \mathrm{W}\right)$. These flows pass through the formation region for the saline Eastern North Atlantic Water, or ENAW (Pollard et al., 1996), and give rise to the salinity pattern illustrated in Fig. 6b, showing the saline waters being swept through the Bay of Biscay and entrained into the SEC at the Goban Spur. Also note that a marked frontal structure forms near the current flowing northward along $14^{\circ} \mathrm{W}\left(42-44^{\circ} \mathrm{N}\right)$, which turns northeastwards into the Bay of Biscay, and also a minor frontal structure associated with the SEC around the Spanish slopes.

Northwards from the Goban Spur, the SEC in ISOPYCNIC flows strongly polewards, splitting to run partly around the western side of the Porcupine Bank and partly between the Bank and the Irish shelf (where there is a topographic saddle point, near $53^{\circ} \mathrm{N}, 12^{\circ} \mathrm{W}$ ). These flows re-join

(a) ISOPYCNIC: Winter Near-Surface Currents $(\mathrm{m} / \mathrm{s})$

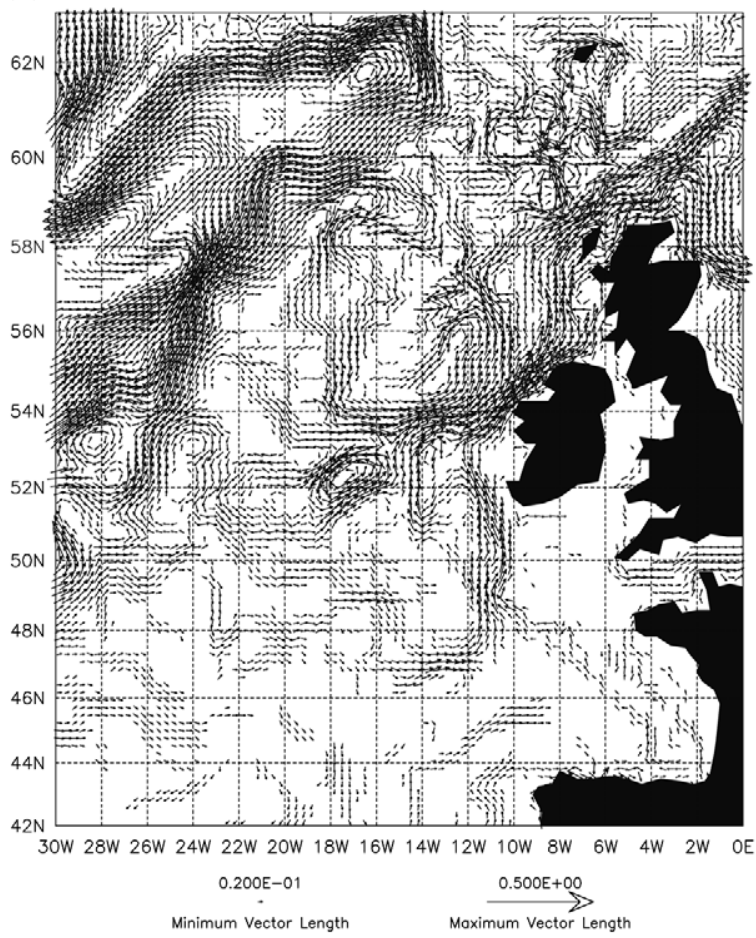

\section{(b) ISOPYCNIC: Winter Near-Surface Currents (psu)}

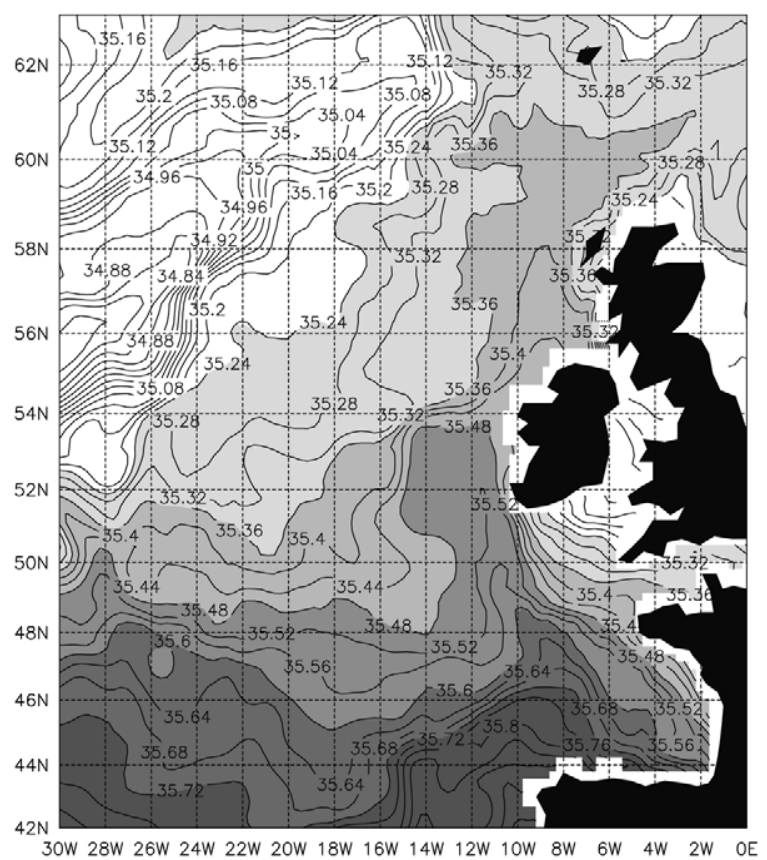

Fig. 6. Winter near-surface $(53 \mathrm{~m})$ characteristics for ISOPYCNIC. (a) currents $(\mathrm{m} / \mathrm{s}$; vector arrows show the velocities at the arrow centres), (b) salinities (grey shades change at salinities of 35.24, 35.36, 35.48, 35.60 and 35.72). 
on the northern side of the Bank $\left(54^{\circ} \mathrm{N}, 12^{\circ} \mathrm{W}\right)$, where they are also augmented by a strong inflow from the west. This western inflow is itself formed from three current branches from the model North Atlantic Current (NAC), two running eastwards between 51 and $55^{\circ} \mathrm{N}$, and one running southwards down $16-20^{\circ} \mathrm{W}$ (the western side of the Rockall Plateau) before turning to the east along $54^{\circ} \mathrm{N}$, and joining the other branches near $54^{\circ} \mathrm{N}, 15^{\circ} \mathrm{W}$. These three branches form a significant input of fresher NAC waters into the southern Rockall Trough. This is reflected by the marked front shown in Fig. $6 \mathrm{~b}$ on the western and northern sides of the Porcupine Bank, and by the import of waters fresher than 35.32 along $54^{\circ} \mathrm{N}$. Note also that the cyclonic eddy observed on the 27.60 surface in Fig. 3a at the southern entrance to the Rockall Trough is also clearly seen in the surface flows here, and that the import of fresher flows from the west along $54^{\circ} \mathrm{N}$ is also observed on both surfaces.

The merger, or partial merger, of these five flows near $54^{\circ} \mathrm{N}, 12^{\circ} \mathrm{W}$ is viewed as a partial mixing of saline waters from the Biscay area (with salinities in the range 35.48-35.50 over the Porcupine Bank) and the somewhat fresher (salinities between 35.28 and 35.36) waters from the west of NAC origin. These waters then form a broad northeastward flow into the Rockall Trough. At $55^{\circ} \mathrm{N}, 9-11^{\circ} \mathrm{W}$, the flows again diverge (as suggested in the schematic by Ellett et al., 1986), with one northward branch, and a northeastward continuation of the SEC along the Irish-Scottish slopes. The northward branch itself splits at $57^{\circ} \mathrm{N}, 12^{\circ} \mathrm{W}$ into northeastward and southwestward branches which cover the western flank of the Rockall Trough. Part of the northeastward of these branches then reforms with the SEC at $58.5^{\circ} \mathrm{N}$ to form a strong flow into the southern Nordic Seas, with the remainder flowing generally northwestwards around the southern flanks of the WTR. These flow patterns are again directly reflected in the surface salinity distribution (Fig. $6 b)$. North from the Porcupine Bank, the highest salinities (typically close to or above 35.40) are carried by the SEC around the eastern slopes and into the southern Nordic Seas. High salinities (35.32-35.36) are also in evidence spreading to fill the western Rockall Trough following the current splitting at $55^{\circ} \mathrm{N}$, and also to the northwest across the WTR in accord with current structure there. Overall, it is clear that saline water masses (ENAW) from the Bay of Biscay are being carried polewards into the Nordic Seas by the SEC, and mixed with NAC-derived waters along the way.

For LEVEL, Fig. 7, the flow structure is broadly similar to that for ISOPYCNIC, save that the effect of the waters from the NAC is slightly stronger, and the general northward flow of saline waters occurs over a larger zonal extent in the region equatorwards of the Rockall Trough. Fig. 7a reveals the SEC in LEVEL running around the Spanish slopes and through the Biscay region to the Goban Spur. Fig. 7b shows that this is associated with the northward advection of the highest salinities (35.56-35.80) in the region. The SEC then splits, the smaller part following the western Porcupine Bank, and the larger part cutting between the Bank and the Irish shelf. At 54$55^{\circ} \mathrm{N}$, on the northern side of the Porcupine Bank, the SEC is affected by branches of fresher (35.44-35.48) NAC-derived water coming from the west. Two of these branches flow southwards between $16-20^{\circ} \mathrm{W}$ (much as for ISOPYCNIC) before turning to the east along $55^{\circ} \mathrm{N}$. At $16^{\circ} \mathrm{W}$, this current is joined by a further branch flowing generally to the northeast and deriving from the NAC near $50-51^{\circ} \mathrm{N}, 28-30^{\circ} \mathrm{W}$. These current branches are associated with clear frontal structures in the surface salinity field which converge with the SEC waters north of the Porcupine Bank $\left(55^{\circ} \mathrm{N}, 10-12^{\circ} \mathrm{W}\right)$.

In the Rockall Trough and further north, the flows are again much as in ISOPYCNIC. The 
(a) LEVEL: Winter Near-Surface Salinity $(\mathrm{m} / \mathrm{s})$

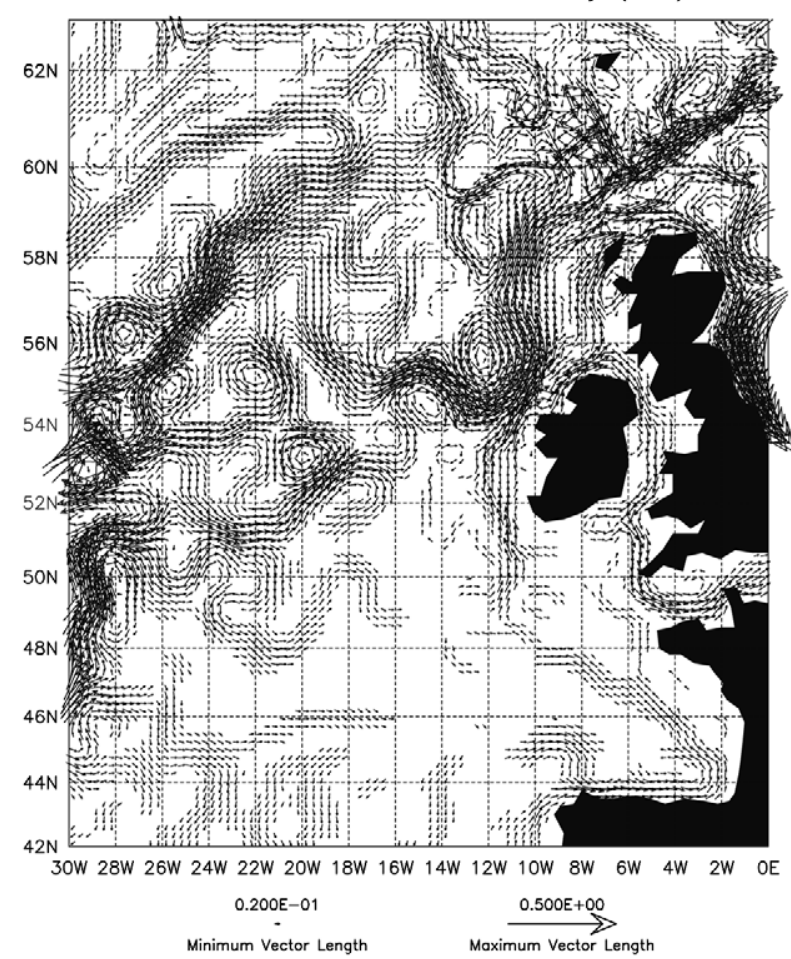

(b) LEVEL: Winter Near-Surface Salinity (psu)

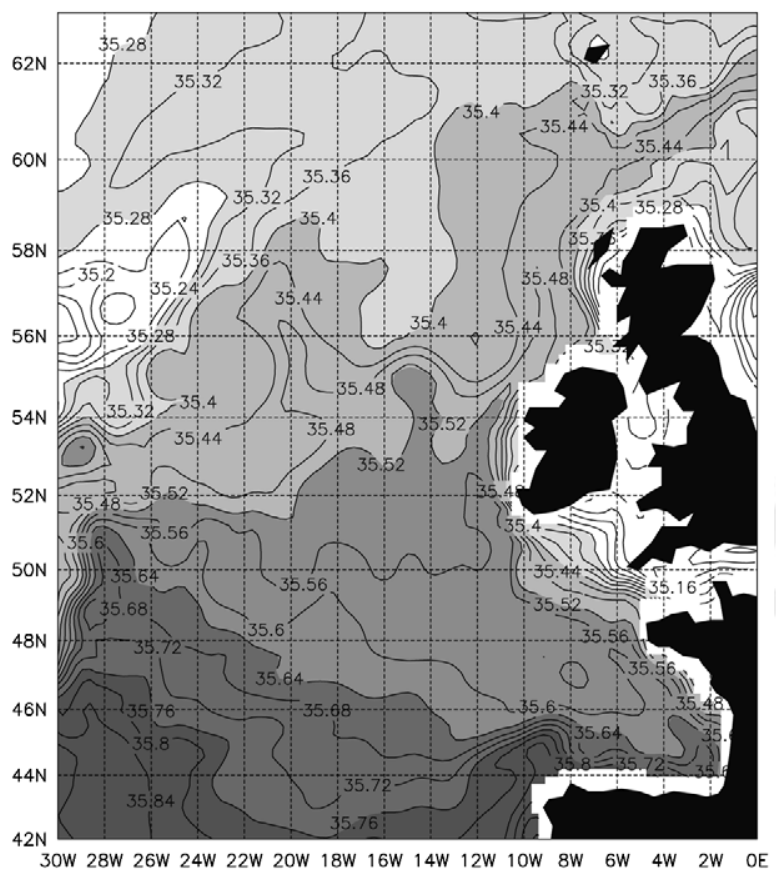

Fig. 7. Winter near-surface $(53 \mathrm{~m})$ characteristics for LEVEL. (a) currents $(\mathrm{m} / \mathrm{s}$; vector arrows show the velocities at the arrow centres), (b) salinities (grey shades change at salinities of 35.28, 35.40, 35.52, 35.64 and 35.76).

currents converge forming a broad northeastward flow north of the Porcupine Bank, but then diverge near $55^{\circ} \mathrm{N}$. This time the greater part of the flow sweeps northwards to fill the central and western side of the Trough, while a smaller portion follows the Irish-Scottish slopes (along a pathway that is slightly inshore of that in ISOPYCNIC). The branch which moves into the western Trough then splits, part recirculating to the southwest, and part to the north and northeast. This latter branch then itself splits near $59^{\circ} \mathrm{N}, 10^{\circ} \mathrm{W}$, the larger part moving over to join with, and form the bulk of, the SEC as it flows into the Nordic Seas. The smaller part, however, circulates to the west around the southern flanks of the WTR. These current branches are again reflected in the salinity structure, which, as for ISOPYCNIC, shows the clear influence of the SEC in transporting the highest salinity water into the Nordic Seas. Westward spreading of saline waters along the southern flank of the WTR (near $60^{\circ} \mathrm{N}$ ) is also apparent.

For SIGMA2, Fig. 8, the situation is again similar to that for the other models, but is perhaps closer to ISOPYCNIC in that the high salinities south of the Porcupine Bank are derived from flows through the Biscay region (i.e. east of $14^{\circ} \mathrm{W}$ ), rather than from a broader region as for LEVEL (e.g. out to $28^{\circ} \mathrm{W}$ ). Fig. 8a shows two northwestward flows through the Bay of Biscay, one over the lower slopes and one over the upper slopes, which converge at the Goban Spur to form the SEC. These flows are supplemented by two current branches from the west which move eastwards through the formation region of the ENAW (closely following contours of surface 
(a) SIGMA2: Winter Near-Surface Salinity $(\mathrm{m} / \mathrm{s})$

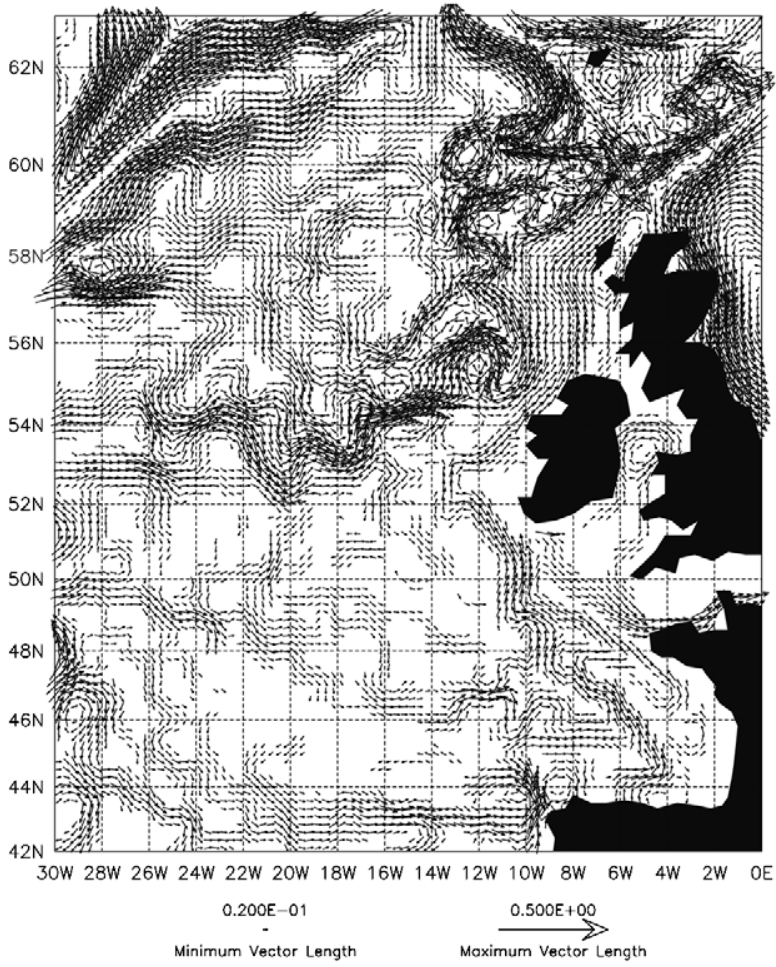

(b) SIGMA2: Winter Near-Surface Salinity (psu)

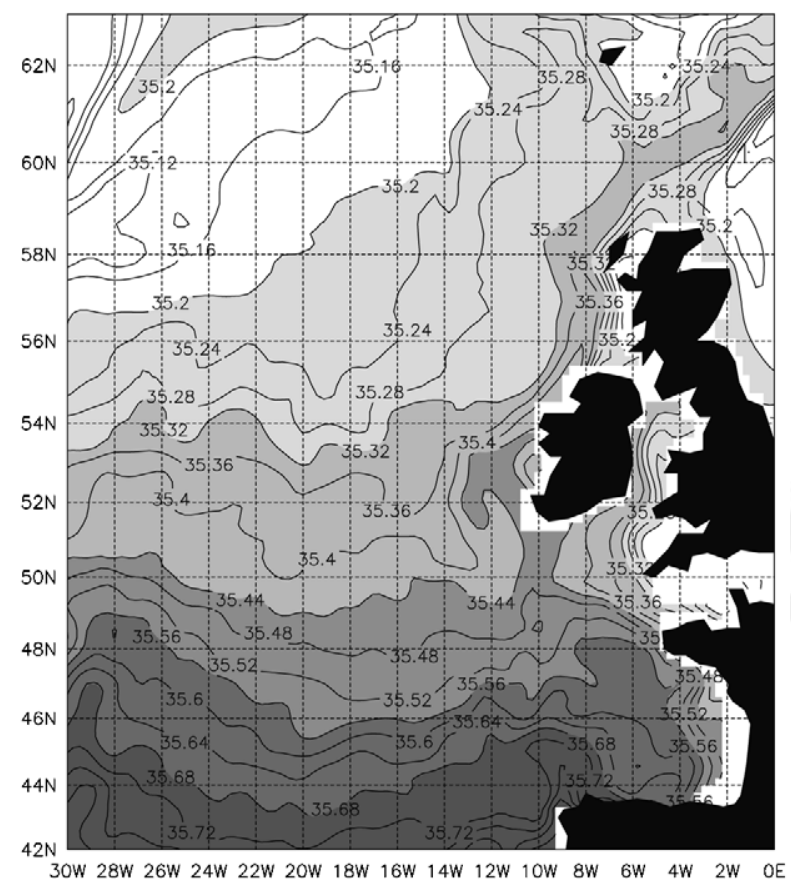

Fig. 8. Winter near-surface $(53 \mathrm{~m})$ characteristics for SIGMA2. (a) currents $(\mathrm{m} / \mathrm{s}$; vector arrows show the velocities at the arrow centres), (b) salinities (grey shades change at salinities of 35.20, 35.32, 35.44, 35.56 and 35.68).

salinity, Fig. 8b) and which impact upon the eastern boundary current system near $43^{\circ} \mathrm{N}$ and between 46 and $48^{\circ} \mathrm{N}$.

Further north, the SEC then follows the western edge of the Porcupine Bank (the necessary smoothing having removed the saddle point with the Irish shelf) and transits onto the slopes west of Ireland. Here at $54-55^{\circ} \mathrm{N}$ it meets with a strong inflow of NAC-derived waters which flow in from the west along approximately $54^{\circ} \mathrm{N}$ (much as in the other models), which is itself partially fed by southward flows in the region $16-21^{\circ} \mathrm{W}$. The salinities in the SEC as it passes around the Porcupine Bank are 35.44-35.46, and those in the inflow along $54^{\circ} \mathrm{N}$ (associated with a frontal structure) are 35.28-35.32. Both of these are close to the salinities of the same features in ISOPYCNIC, although those in LEVEL are slightly more saline. (Note the change of contour values denoted by the same grey shades in Figs. $6 \mathrm{~b}, 7 \mathrm{~b}$ and $8 \mathrm{~b}$, which were chosen to span the range of salinities in the northward sweep of the SEC in the respective models). The currents in SIGMA2 then briefly converge to form a broad northward flow through $56^{\circ} \mathrm{N}$, but then the western portion of this flow separates, moving over to the western side of the Rockall Trough, as for the other models, leaving a broad SEC on the eastern side. These two flows largely re-merge just south of the WTR (near 59-60'), and then go on to form the SEC flowing into the Nordic Seas, and also a strong westward-northwestward flow southwest of the Faeroes. The flow pattern through this region is again reflected in the salinity structure, which shows a tightly confined 
SEC carrying the highest salinities into the Nordic Seas (as well as somewhat less saline waters northwestwards past the Faeroes).

Overall, the upper-layer circulation patterns in all the models agree remarkably well with the schematic circulation figure of Ellett et al. (1986, Fig. 4). In particular, Ellett's schematic shows a general merging of flows from the south and southwest on the western Porcupine slopes, near $53^{\circ} \mathrm{N}$, with a large eddy standing at the southern entrance to the Rockall Trough. The flows then re-separate on the northern Porcupine slopes (at $54^{\circ} \mathrm{N}, 13^{\circ} \mathrm{W}$ ), with one branch continuing northeastwards as the SEC, and one branch flowing north-northeast across the central Trough. This latter branch reaches the western side of the Trough near $57^{\circ} \mathrm{N}$, and part of this turns back to flow southwards down the eastern side of the Rockall Bank. The main part, however, continues to flow northeastwards and re-merges with the SEC near $58^{\circ} \mathrm{N}$, before continuing on into the Nordic Seas.

There are thus two main northward flows through the Rockall Trough at $57-58^{\circ} \mathrm{N}$ (both in the observations and the models), the SEC on the eastern slopes, and a further general northward flow in the central and western Trough, which we shall refer to as the Rockall Trough Current (RTC) for convenience. Observations (Huthnance, 1986; Hill \& Mitchelson-Jacob, 1993) show the SEC at $57.5-58^{\circ} \mathrm{N}$ as a northward flow with typical current speeds of $15 \mathrm{~cm} / \mathrm{s}$, which is centred on the slope in water depths of 300-500 m between 9.0 and $9.5^{\circ} \mathrm{W}$, with an across-slope width of $30 \mathrm{~km}$. The flow in the remainder of the Rockall Trough (in the observations) takes the form of a pronounced northward flow typically between 12.0 and $12.5^{\circ} \mathrm{W}$ (again with an acrosscurrent width of $30 \mathrm{~km}$ ), which reaches typically $10-15 \mathrm{~cm} / \mathrm{s}$, but occasionally $20-30 \mathrm{~cm} / \mathrm{s}(\mathrm{N}$. P. Holliday, D. Smythe-Wright, personal communication). This current typically extends to depths of 750-1000 m, and is accompanied by southward recirculation on the eastern side of the Anton Dohrn Seamount $\left(10-11^{\circ} \mathrm{W}\right.$, around which there is generally an anticyclonic circulation). Huthnance (1986) estimated the transport in the SEC at $58^{\circ} \mathrm{N}$ as $1.5 \mathrm{~Sv}$, while Ellett et al. (1986) reported the mean northward 'RTC' transport in the upper $500 \mathrm{~m}$ of the deep portion of the Trough at $57.5^{\circ} \mathrm{N}$ (i.e. including all southward recirculations but excluding the SEC contribution) as $2.7 \mathrm{~Sv}$. More recent geostrophic calculations for the $57.5^{\circ} \mathrm{N}$ section (N. P. Holliday, personal communication) estimate the mean transport (above $500 \mathrm{~m}$ ) in the SEC as $1.9 \mathrm{~Sv}$, and that in the RTC (also above $500 \mathrm{~m}$, and excluding all boundary current flows) as $1.2 \mathrm{~Sv}$. (See also Holliday, Pollard, Read \& Leach, 2000, for transports above $1200 \mathrm{~m}$.)

For comparison, Fig. 9 shows sections of northward velocity (annual means) at $57.5^{\circ} \mathrm{N}$ in the models (section 2 in Fig. 1a). For ISOPYCNIC (Fig. 9a), the RTC reaches $11 \mathrm{~cm} / \mathrm{s}$ near the surface at $12.5^{\circ} \mathrm{W}$ (with a secondary maximum of $9 \mathrm{~cm} / \mathrm{s}$ at $11.5^{\circ} \mathrm{W}$ ), and decreases with depth. The net transport above $500 \mathrm{~m}$ in the RTC (from the western slope to $10^{\circ} \mathrm{W}$ ) is $4.8 \mathrm{~Sv}$. The SEC is a near-surface current (largely in the upper $600 \mathrm{~m}$ ) which reaches $7 \mathrm{~cm} / \mathrm{s}$ at $9.5^{\circ} \mathrm{W}$, and decreases onto the shelf. (There is a second maximum further onto the shelf, reaching $7 \mathrm{~cm} / \mathrm{s}$ at $8^{\circ} \mathrm{W}$, but the realism of this feature is unknown.) The width of the SEC in ISOPYCNIC is 85 $\mathrm{km}\left(8.6-10.0^{\circ} \mathrm{W}\right.$ ) and the transport (above $500 \mathrm{~m}$ ) is $1.6 \mathrm{~Sv}$. For LEVEL (Fig. 9b), the RTC is centred at $11^{\circ} \mathrm{W}$ where maximum current speeds of $10 \mathrm{~cm} / \mathrm{s}$ are observed, and this has a transport of $5.3 \mathrm{~Sv}$ (above $500 \mathrm{~m}$ and westwards of $9.8^{\circ} \mathrm{W}$ ). The SEC (70 km wide) is again an identifiable maximum (over $6 \mathrm{~cm} / \mathrm{s}$ ) located on the eastern slopes (centred at $9.5^{\circ} \mathrm{W}$ ), and its transport (in the top $500 \mathrm{~m}$, between 8.6 and $9.8^{\circ} \mathrm{W}$ ) is $1.3 \mathrm{~Sv}$. Again, there is a secondary maximum further onto the shelf (over $12 \mathrm{~cm} / \mathrm{s}$ at $7.3^{\circ} \mathrm{W}$ ). In SIGMA2 (Fig. 9c), the RTC has maxima of $10 \mathrm{~cm} / \mathrm{s}$ 
(a)

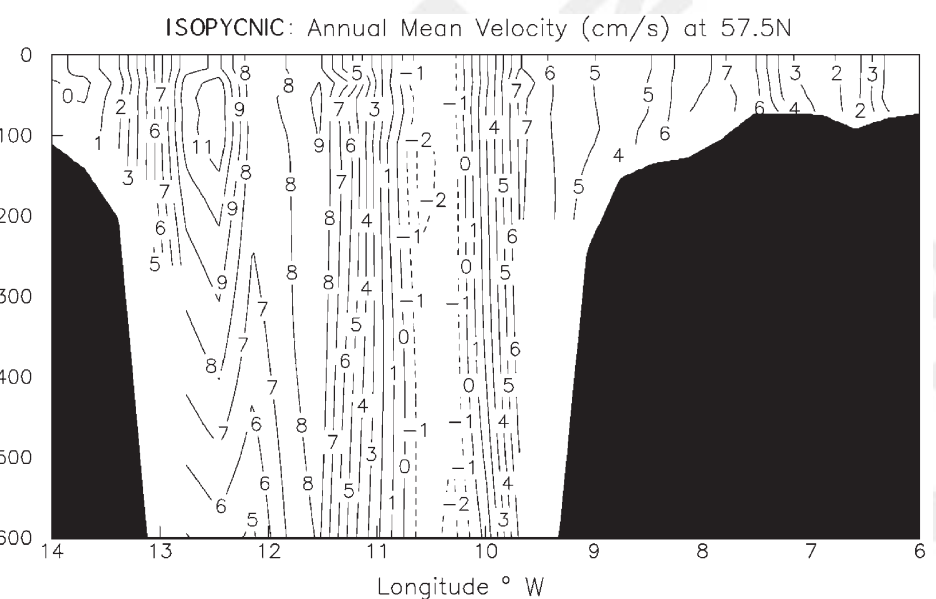

(b)

LEVEL: Annual Mean Velocity $(\mathrm{cm} / \mathrm{s})$ at $57.5 \mathrm{~N}$

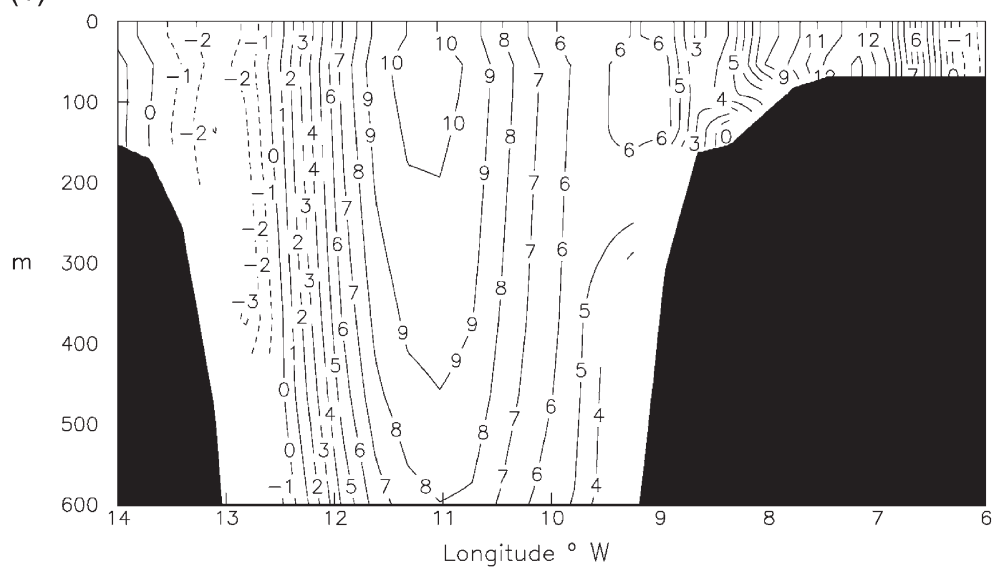

(c)

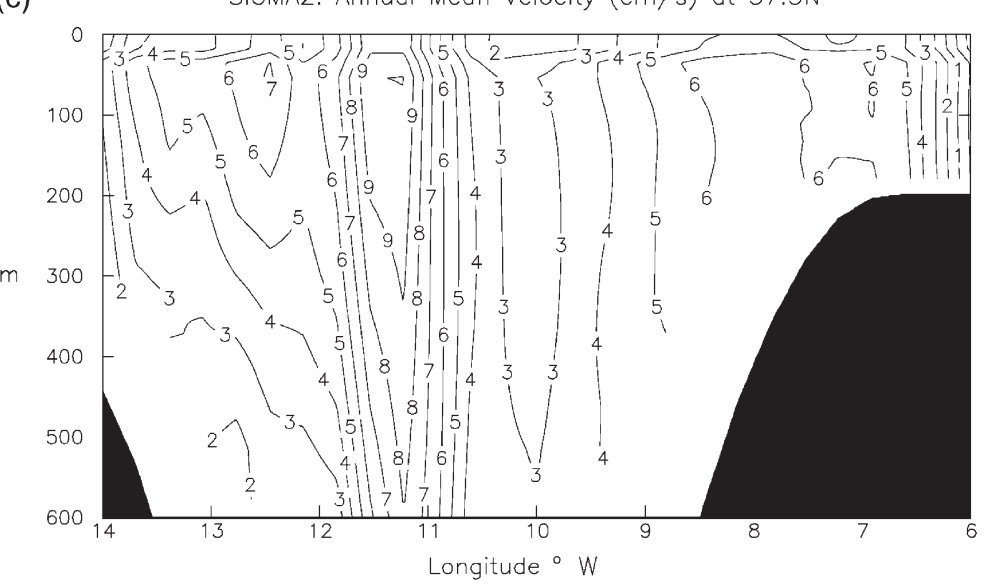

Fig. 9. Sections of annual-mean northward velocity $(\mathrm{cm} / \mathrm{s})$ across the Rockall Trough at $57.5^{\circ} \mathrm{N}$ (section 2 in Fig. 1(a)) for (a) ISOPYCNIC, (b) LEVEL and (c) SIGMA2. Negative values (southward flow) are denoted by dashed contours, and the vertical axis shows depth in $\mathrm{m}$. 
at $11.3^{\circ} \mathrm{W}$, and a secondary maximum of $7 \mathrm{~cm} / \mathrm{s}$ at $12.5^{\circ} \mathrm{W}$, together with a net transport (westwards of $10^{\circ} \mathrm{W}$ ) of $5.7 \mathrm{~Sv}$. The SEC is evident as a broad current between $10^{\circ} \mathrm{W}$ and $7.4^{\circ} \mathrm{W}$ $(160 \mathrm{~km}$ wide), and has a transport (above $500 \mathrm{~m})$ of $3.3 \mathrm{~Sv}$. Again, there is an indication of a secondary maximum further onto the slope, at $7^{\circ} \mathrm{W}$.

Turning now to the salinities in the core of the SEC, these have been reported as close to 35.40 near the Porcupine Bank (White \& Bowyer, 1997) and between 35.38 and 35.40 at $58-59^{\circ} \mathrm{N}$ (Hill \& Mitchelson-Jacob, 1993). ISOPYCNIC shows core SEC salinities of 35.48 at Porcupine and 35.40 at $58^{\circ} \mathrm{N}$, while LEVEL has 35.52 at Porcupine and 35.48 at $58^{\circ} \mathrm{N}$ (about 0.06 higher than ISOPYCNIC on average). SIGMA2, on the other hand, shows salinities of 35.44 at Porcupine and 35.36 at $58^{\circ} \mathrm{N}(0.04$ fresher than ISOPYCNIC at both locations). The models are therefore all slightly more saline at Porcupine Bank than the observations (SIGMA2 being the most realistic), but cluster around the observed salinity at $58^{\circ} \mathrm{N}$ (with ISOPYCNIC being the most realistic). However, recent studies (Holliday et al., 2000) show a large interannual variability in salinity, of up to \pm 0.05 , in the upper ocean salinity at $57.5^{\circ} \mathrm{N}$ in the Rockall Trough, and the same may be true elsewhere. Consequently, the model SEC salinities can probably be counted as falling mostly within the expected range of the SEC salinities in the real world.

\section{Winter mixing}

We now investigate whether, and how, the near-surface waters transported northwards by the SEC/NAC system are able to affect the properties on the MOW (27.60) density surface, and in particular, whether they provide an explanation of the high salinities seen (especially in ISOPYCNIC and LEVEL) in the northern Rockall Trough, near the WTR, and in the southern Nordic Seas. Consequently, Fig. 10 presents salinity sections in the Faeroe-Shetland Channel in ISOPYCNIC running northwards from the WTR (along section 3 in Fig. 1a), as it turns out that this is the primary site at which the near-surface water masses in the SEC/NAC are actively mixed down to affect the 27.60 layer (in all models). These figures also show the location of the 27.60 surface (grey shading).

Fig. 10a shows the situation in fall, before winter mixing has commenced. At this time of year, the mixed layer forms a relatively fresh layer about $100-150 \mathrm{~m}$ thick, which caps a more saline core lower down, at depths of 150-300 m, in which the maximum salinities are 35.34. The capping of this core corresponds with the observed structure of the SEC (a little further south) at about this time of year (Hill \& Mitchelson-Jacob, 1993). We also note that the 27.60 isopycnal lies below the saline SEC core, and is at depths of 400-350 m between 6 and $4^{\circ} \mathrm{W}$, thereafter rising gently to the east (and north) to reach $150 \mathrm{~m}$ deep at $2^{\circ} \mathrm{W}$. Throughout most of this section (except east of $2.5^{\circ} \mathrm{W}$ ), this isopycnal surface is closely isohaline, with salinities of 35.31 . In the winter, Fig. 10b, the surface mixing extends to depths of 350-400 m, and the high salinities (35.34-35.36) in the SEC now reach from these depths to the sea-surface (see also Fig. 6b), again corresponding with the reported SEC structure (Hill \& Mitchelson-Jacob, 1993). Furthermore, it is clear that this deep surface mixing is now interacting with the 27.60 surface. Although the salinity along this surface between 6 and $5^{\circ} \mathrm{W}$ is still 35.31 , the salinity between 5 and $3^{\circ} \mathrm{W}$ has risen to 35.32-35.33, indicating the onset of detrainment (and possibly vertical mixing) through the mixed layer base. Furthermore, the 27.60 isopycnal has outcropped to the surface near $3^{\circ} \mathrm{W}$, 
(a) ISOPYCNIC: F. S. Channel fall Salinity $(60-62 \mathrm{~N})$

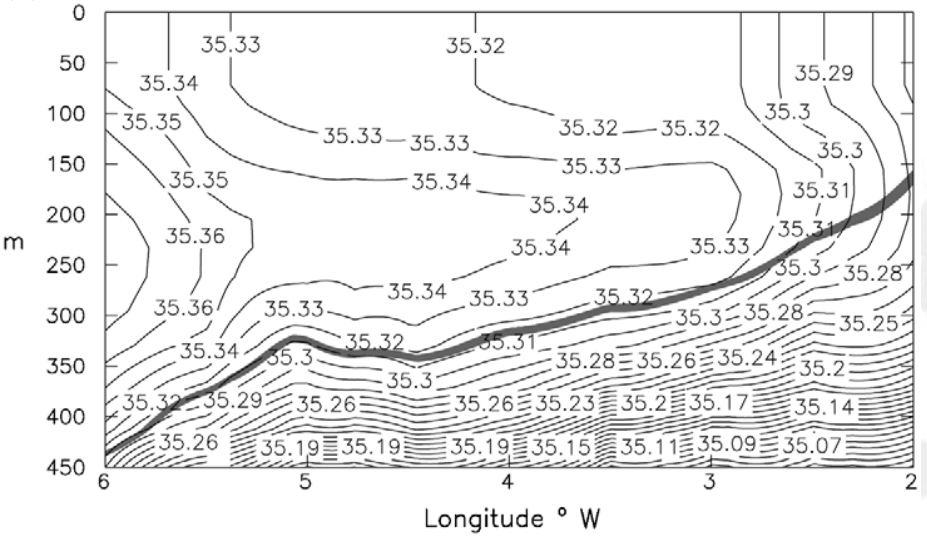

(b) ISOPYCNIC: F.-S. Channel Winter Salinity (60-62N)

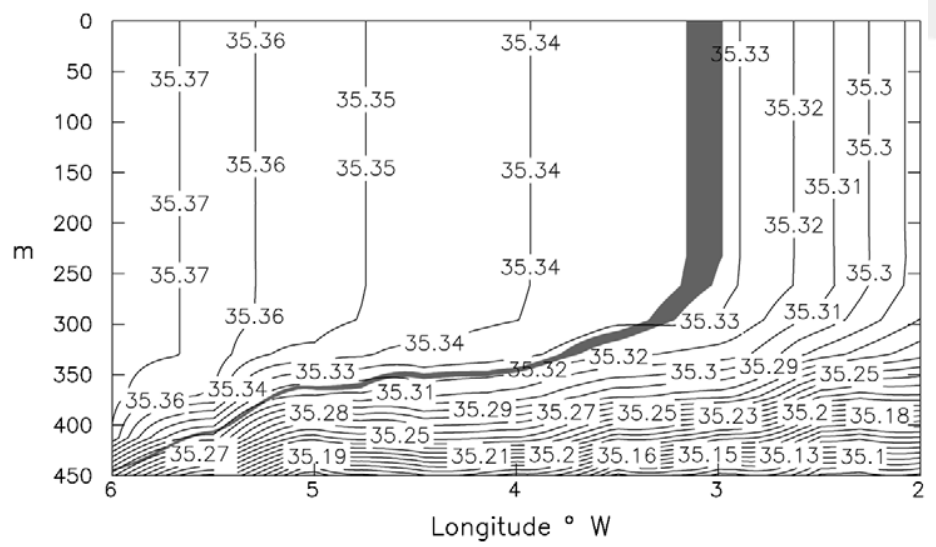

(c) ISOPYCNIC: F.-S. Channel Spring Salinity $(60-62 \mathrm{~N})$

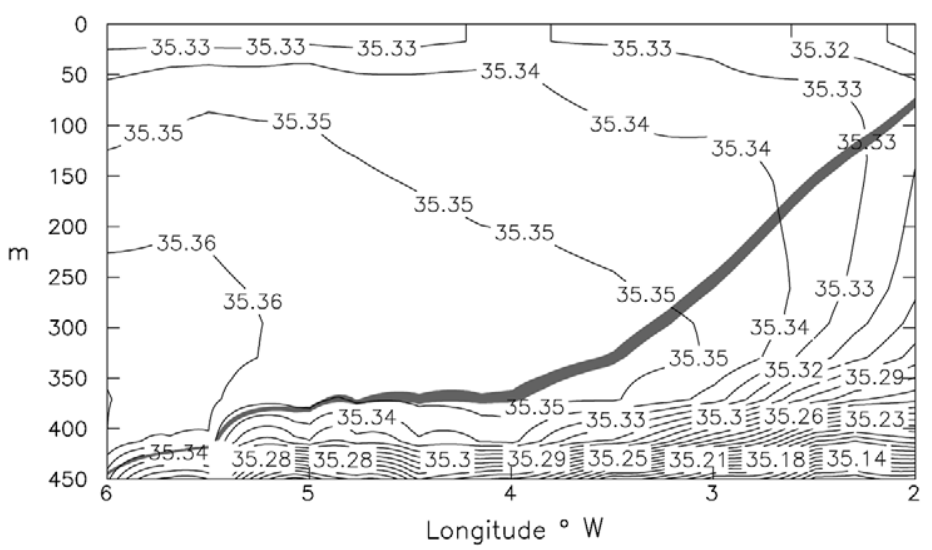

Fig. 10. Sections for ISOPYCNIC in the Faeroe-Shetland Channel between $60^{\circ} \mathrm{N}, 6^{\circ} \mathrm{W}$ and $62^{\circ} \mathrm{N}, 2^{\circ} \mathrm{W}$ (section 3 in Fig. 1(a)) showing salinity (contours) and the 27.60 density surface (grey shading) for (a) fall (grey shading between densities of 27.590 and 27.610), (b) winter (grey shading between densities of 27.595 and 27.605) and (c) spring (grey shading between densities of 27.596 and 27.604). The vertical axis shows depth in $\mathrm{m}$. 
implying that the mixed layer (in the mean winter state) is of this density at this location, and that there are strong interactions between the two. Finally, Fig. 10c shows the situation in spring, and reveals the effects of the completed winter mixing. Although the upper $25-50 \mathrm{~m}$ is already starting to restratify, forming a (thin) fresh capping layer, the primary effect of the winter mixing is to leave behind a thick wedge of saline water detrained from the mixed layer. This reaches about $400 \mathrm{~m}$ in depth, and comprises salinities of 35.34-35.36, agreeing closely with the (mean) winter surface salinities in Fig. 6b near this location. Clearly, the 27.60 surface has also been affected, and salinities on this isopycnal have increased to typically 35.35 throughout most of the section, an increase of 0.04 as compared to the situation in the fall.

For a complementary view, Fig. 11a now presents the spring salinity in ISOPYCNIC on the 27.60 surface (shown shaded where it exists) over the northern Rockall Trough, Wyville-Thomson Ridge (WTR), and Faeroe-Shetland Channel (FSC). The highest salinities, of 35.35-35.36, are in the southern FSC $\left(60.5-61.5^{\circ} \mathrm{N}, 8-3^{\circ} \mathrm{W}\right)$ and have resulted, as above, from detrainment from the winter mixed layer (which has salinities of these values in this region, see Fig. $6 \mathrm{~b}$ ). In the fall, the salinities in this area are only 35.30-35.32, so that the winter mixing has resulted in a considerable increase. Furthermore, we see by comparison with Fig. 4a that these high salinities are being advected northeastwards by the SEC along the southern side of the FSC, and also westwards and southwestwards over the WTR. These latter waters therefore provide a high salinity source in the northern Rockall Trough on this density surface, so that salinities of 35.35-35.36 are observed here (as opposed to values of 35.34 in the fall). These high salinity waters then sweep southwards around (primarily) the western flanks of the Trough, with gradually reducing salinities resulting from mixing with the slightly fresher water masses here (see Figs. 11a, 3a and $4 a)$.

The same process also occurs in the same region in the other two models. Fig. 11b shows the situation for LEVEL. The high salinities in spring (35.37-35.38) in the FSC have again resulted from downward winter mixing and detrainment of saline water masses, with salinities in the fall in this area reaching only 35.34-35.35. As for ISOPYCNIC, these highest salinities are being carried northeastwards in the FSC, and also westwards and southwards into the northern Rockall Trough, forming a high salinity source there (with salinities over 35.36, as compared to values of 35.35 in the fall). For SIGMA2, Fig. 11c, the locally high spring salinities in the FSC, of about 35.26, have again been formed by the same process, with salinities in the fall in this area being only 35.22-35.24. These high spring salinities are being advected northeastwards in the FSC, northwestwards on the southwestern side of the Faeroes, and also southwestwards over the WTR into the northern Rockall Trough (see also Fig. 4c). However, instead of providing a high salinity source here as for the other two models, these latter waters then meet the even more saline MOW, and provide a source of relatively fresh water (which is still, however, more saline in the spring, 35.26-35.27, than in the fall, 35.25-35.26) advecting around the northwestern flanks of the Trough.

\section{Summary and discussion}

In this paper we have used three high-resolution ocean circulation models of the North Atlantic, differing chiefly in their description of the vertical coordinate, to investigate the routes and mechanisms by which saline water masses of southern origin provide inflows to the Nordic Seas. 
(a)

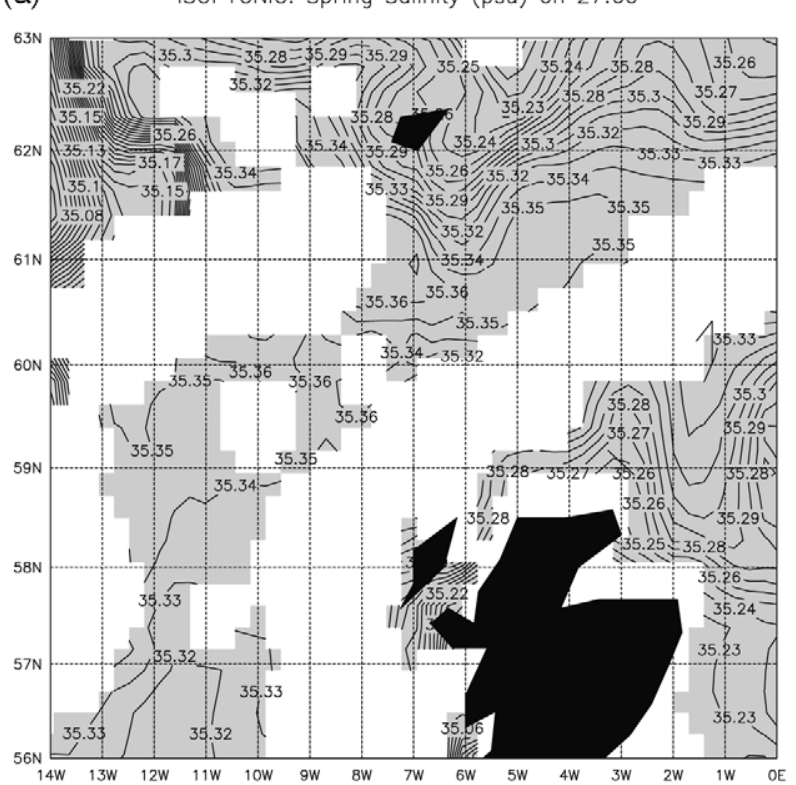

(b)

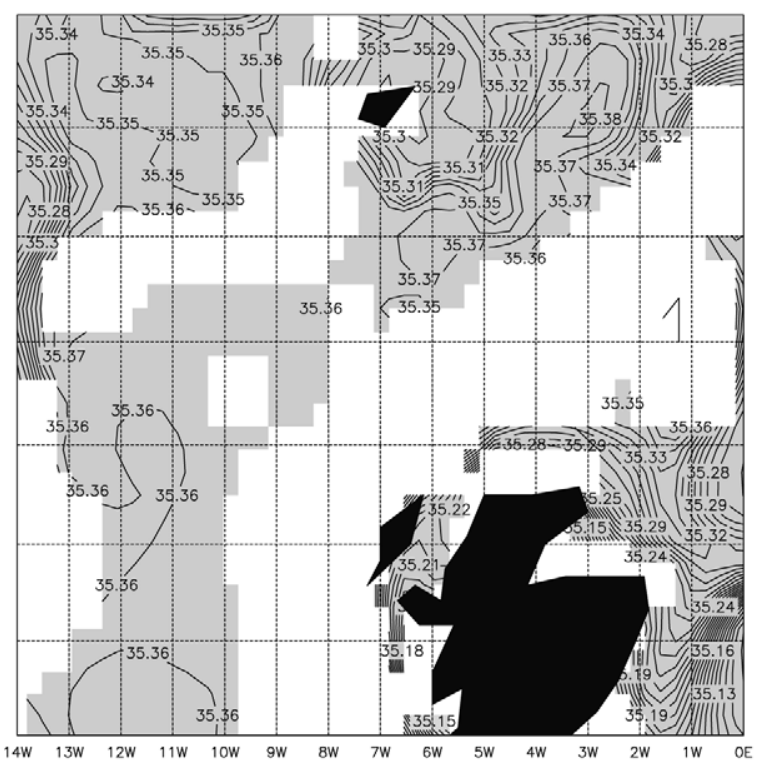

(c)

SIGMA2: Spring Salinity (psu) on 27.60

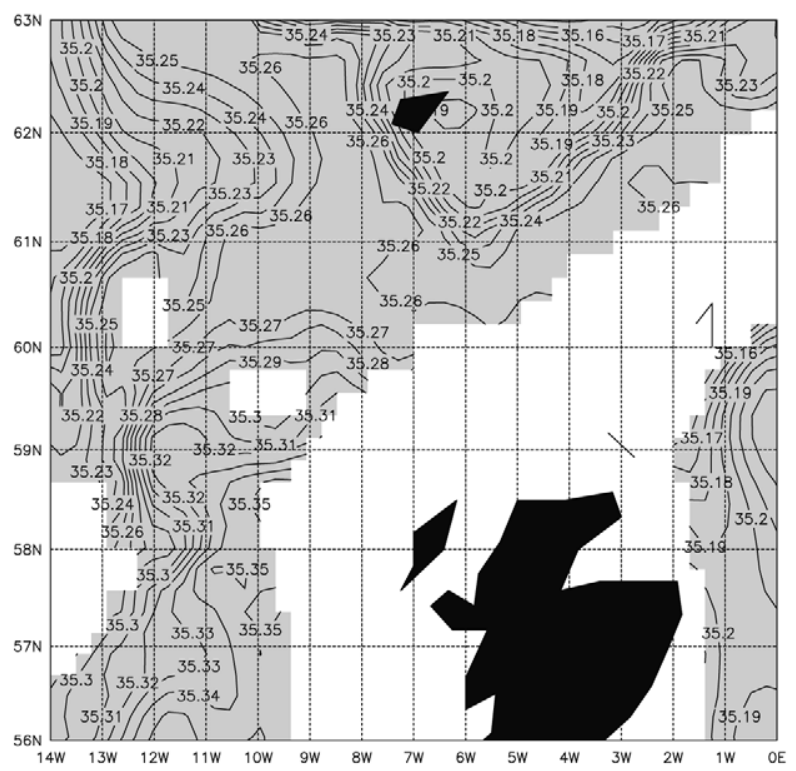

Fig. 11. Spring salinity on the 27.60 density surface for (a) ISOPYCNIC, (b) LEVEL and (c) SIGMA2. Grey shading denotes the existence of the layer. 
Considering firstly inferences from observations, Reid (1979) proposed that Mediterranean Overflow Water (MOW) could provide a deep saline source for these inflows to the Nordic Seas. He conjectured that the MOW would be carried polewards in an eastern boundary undercurrent along a density surface which would rise from depth to shallow enough depths to pass over the Wyville-Thomson Ridge (WTR), and continued further northwards. However, while the presence of high salinity water in the southern Nordic Seas is well supported by the observational data, Reid (1979) used a dataset which was sparse in the Rockall Trough. In particular, it contained no data from between about $52^{\circ} \mathrm{N}$ and $57^{\circ} \mathrm{N}$, which in this study is shown to be a critical and dynamic area. This lack of data may explain why Reid (1979) overlooked or did not find the salinity minimum near $54^{\circ} \mathrm{N}$, which is evident not only in Levitus (see Fig. 2a), but also in the isopycnally-averaged dataset of Lozier et al. (1995, their Fig. 15). However, the datasets of Levitus (1982) and Lozier et al. (1995) do not resolve fine-scale boundary currents, so the apparent presence of the salinity minimum on the northern Porcupine Bank does not necessarily preclude the possibility of MOW being transported northwards in a thin, inshore boundary current, as conjectured by Reid (1979). On the other hand, neither of these datasets offer any direct evidence supporting such a postulate. Furthermore, Ellett et al. (1986) have shown that over the WTR, the flow of water masses on density surfaces appropriate to the MOW is typically southwestwards, which again counts against the above 'Reid hypothesis'.

The 'Reid hypothesis' has also been called into question by the recent observations of McCartney and Mauritzen (2001), who showed that the poleward undercurrent carrying the MOW fades away once it has reached the Porcupine Bank, and does not provide an inflow entering the Rockall Trough. Instead, the latter authors proposed that a branch of the North Atlantic Current may be flowing northwards through the Rockall Trough, and providing a shallow source for the saline inputs into the Nordic Seas. This idea is supported by the well-known northward transport of upper-layer waters though the central Rockall Trough (Ellett et al., 1986; Pingree, 1993). However, an insufficiency of observational data prevented both Reid (1979) and McCartney and Mauritzen (2001) from being able to adequately consider the role of the Shelf Edge Current (SEC) in this respect. The SEC (summarised by Huthnance, 1986) is a generally poleward flow around the European upper continental slopes, and provides a third alternative for the saline inputs to the Nordic Seas.

The potential importance of the supply of saline water masses to the Nordic Seas (which could drive a significant component of the entire Atlantic thermohaline overturning), and the disparate views derived from the observations, have therefore motivated this present study using highresolution basin-wide ocean circulation models. These models, by covering a large proportion of the Atlantic, are not subject to imposed (and to some extent artificial) boundary conditions near the region of interest, as is the case for most limited area model studies, and so provide a suitable vehicle for the present investigation.

We find that in two of the present models, ISOPYCNIC and LEVEL, the MOW flows northwards in an eastern boundary undercurrent, but only as far as the Porcupine Bank at $53^{\circ} \mathrm{N}$, where its progress further to the north is blocked by the presence of strong, quasi-stationary eddies topographically locked in place, and also by branches of the NAC coming from the west. These NAC branches inject fresher waters into the eastern boundary on the MOW density surface near $54-55^{\circ} \mathrm{N}$. In only one of the models, SIGMA2, does MOW invade the Rockall Trough, reaching nearly to $60^{\circ} \mathrm{N}$. However, in none of the models is MOW able to progress northwards into the 
Nordic Seas. All three models are in agreement in showing that the flow on the MOW density surface is to the south and west over the Wyville-Thomson Ridge, and so discount the Reid hypothesis.

Instead, the present study provides the view that the inflows are derived from shallow sources, and comprise both waters of western origin, carried by branches of the North Atlantic Current (NAC), and the more saline Eastern North Atlantic Water (ENAW), transported northwards in the SEC (Shelf Edge Current). The northward flow of the most saline waters is derived primarily from flow through the Bay of Biscay region in ISOPYCNIC and SIGMA2 in the SEC (i.e. the region extending out to $15^{\circ} \mathrm{W}$ at $50^{\circ} \mathrm{N}$ ), but from a broader region in LEVEL (extending out to $28^{\circ} \mathrm{W}$ at $50^{\circ} \mathrm{N}$ : the northwestern limit of this is a southerly branch of the NAC, the inshore boundary is the SEC). In all models, however, it is the SEC that carries the most saline water northwards through the Rockall Trough (i.e. between 54 and $60^{\circ} \mathrm{N}$ ). Moreover (also in all models), branches of the NAC bring relatively fresh upper-layer water in from the west which impacts (at $16^{\circ} \mathrm{W}$ ) upon the eastern boundary system near $53-55^{\circ} \mathrm{N}$, and thereafter converges at least partially and temporarily with the SEC. These flows separate again near $55^{\circ} \mathrm{N}$ to fill the Rockall Trough (with fresher waters on the western side), before largely re-merging south of the WTR (near $59^{\circ} \mathrm{N}$ ) to form a strong inflow into the Nordic Seas.

We have also shown that downward wintertime mixing of these saline water masses in the Faeroe-Shetland Channel affects the density surfaces appropriate to the MOW and provides a source of high salinity for these density surfaces which sweeps both northwards into the Nordic Seas and southwards into the Rockall Trough. This northern source of southwestward-spreading saline water, coupled with the impact of fresher waters near $54^{\circ} \mathrm{N}$ carried in by the NAC on these density surfaces, and the northward fading of the MOW undercurrent, explains the salinity minimum near the Porcupine Bank in ISOPYCNIC and LEVEL. The same processes may therefore also explain the the salinity minimum observed near $54^{\circ} \mathrm{N}$, and the increasing salinities further north (Levitus, 1982; Lozier et al., 1995).

It is possible that the penetration of the MOW into the Rockall Trough in SIGMA2 (but not in the other models) may result, at least partially, from this model's smoother bathymetry, which provides broader continental slopes. For instance, Huthnance (1987) has shown that the alongslope distance of influence of topographically constrained currents is proportional to the speed of the lowest mode shelf wave (multiplied by a decay timescale), which is in turn proportional to the effective width of the slope (which can be seen from Huthnance, Mysak \& Wang, 1986, or deduced from the non-dimensional equations when divergence is neglected). Consequently, broader slopes may be expected to lead to an enhancement of along-slope penetration of the relevant topographically-steered flows.

Overall, the models agree remarkably well with available inferences from the observations, so giving support to the conclusions reached above. In particular, the upper ocean current pathways in the models show a close resemblance to those of Ellett et al. (1986), and the deeper flow patterns are supported by the findings of McCartney and Mauritzen (2001) (except that MOW flows into the Rockall Trough according to SIGMA2). We also note that, in all the models, the currents in the Rockall Trough area are generally slower and broader than in Nature, perhaps as might be expected from models of this resolution $(20 \mathrm{~km})$. However, the SECs at $57.5^{\circ} \mathrm{N}$ in ISOPYCNIC and LEVEL give realistic estimates of transport, whereas those in SIGMA2 are somewhat too strong. The strength of the flow in the central Rockall Trough at $57.5^{\circ} \mathrm{N}$ (in the 
'Rockall Trough Current') is also stronger in all the models than the observations would suggest; this may be because the models are unable to capture adequately the observed southward recirculation on the eastern side of the Anton Dohrn Seamount (though ISOPYCNIC, with the most realistic Seamount, does best in this respect). Nonetheless, in all the models, the SEC is confined within the upper 500-600 $\mathrm{m}$ of the water column, which is in accord with the observations. Furthermore, we also reiterate that the salinities in the model SECs (near $57.5^{\circ} \mathrm{N}$ ) mostly fall encouragingly within the range of expectations derived from the observations.

In order to quantify explicitly the relative roles of the NAC and the SEC in transporting saline water masses through the Rockall Trough and on into the Nordic Seas, Table 1 presents mean salinities, and volume and salinity transports, at $50^{\circ} \mathrm{N}, 16^{\circ} \mathrm{W}$ and $59^{\circ} \mathrm{N}$. (This has been undertaken for the winter mean case (see below for justification), and for the upper $500 \mathrm{~m}$ of the water column, $500 \mathrm{~m}$ being the approximate depth of the Wyville-Thomson Ridge which restricts the flow into the Nordic Seas). With reference to Figs. 6-8, we define the northward flow around the continental slopes at $50^{\circ} \mathrm{N}$ (between the longitudes shown in the Table) as the SEC input to the southern Rockall Trough. Likewise, we define the NAC input as the (main) eastward flow through $16^{\circ} \mathrm{W}$ and north of $50^{\circ} \mathrm{N}$ (between the latitudes shown). We also make comparisons of these two inputs to the Trough with the northward flow through $59^{\circ} \mathrm{N}$ (where the various northward currents have largely re-merged), considered as the output from the northern Rockall Trough into the Nordic Seas. This we refer to as the Northern Rockall Outflow (NRO) in the table and below. (Any mismatch between the summed transports from the two southern inputs and the northern output thus defined can mostly be attributed either to flows through the northwestern boundary of the Trough, or else to unsteadiness in the circulation patterns.)

Table 1 shows that for ISOPYCNIC, the SEC and NAC inputs are similar, with volume transports just less than $4 \mathrm{~Sv}$, and salinity transports of about 140-145 $\mathrm{kT} \mathrm{s}^{-1}$ (kilotons per second). These compare with 'outputs' through $59^{\circ} \mathrm{N}$ of $5 \mathrm{~Sv}$ and $181 \mathrm{kT} \mathrm{s}^{-1}$ respectively. Thus the SEC

Table 1

Winter mean average salinity, $S_{\mathrm{av}}$, volume transport, $V(\mathrm{~Sv})$, and salinity transport $F\left(\mathrm{kT} \mathrm{s}^{-1}\right)$, for the upper $500 \mathrm{~m}$ of the water column, on the shown sections, and for each model. The sections are appropriate for the flows denoted SEC (Shelf Edge Current), NAC (North Atlantic Current), and NRO (Northern Rockall Outflow), see text for details. $V$ and $F$ are positive northwards (for the $50^{\circ} \mathrm{N}$ and $59^{\circ} \mathrm{N}$ sections) or eastwards (for the $16^{\circ} \mathrm{W}$ sections)

\begin{tabular}{|c|c|c|c|c|c|}
\hline Model & Flow & Section & $S_{\mathrm{av}}$ & $\begin{array}{l}V \\
(\mathrm{~Sv})\end{array}$ & $\begin{array}{l}F \\
\left(\mathrm{kT} \mathrm{s}^{-1}\right)\end{array}$ \\
\hline \multirow[t]{3}{*}{ ISOPYCNIC } & SEC & $50^{\circ} \mathrm{N}, 14-10^{\circ} \mathrm{W}$ & 35.50 & 3.77 & 138 \\
\hline & NAC & $16^{\circ} \mathrm{W}, 53-55^{\circ} \mathrm{N}$ & 35.31 & 3.99 & 145 \\
\hline & NRO & $59^{\circ} \mathrm{N}, 9^{-} 3^{\circ} \mathrm{W}$ & 35.35 & 4.98 & 181 \\
\hline \multirow[t]{3}{*}{ LEVEL } & SEC & $50^{\circ} \mathrm{N}, 13-10^{\circ} \mathrm{W}$ & 35.56 & 1.57 & 58 \\
\hline & NAC & $16^{\circ} \mathrm{W}, 55-56.5^{\circ} \mathrm{N}$ & 35.43 & 6.27 & 228 \\
\hline & NRO & $59^{\circ} \mathrm{N}, 12-4^{\circ} \mathrm{W}$ & 35.44 & 8.11 & 295 \\
\hline \multirow[t]{3}{*}{ SIGMA2 } & SEC & $50^{\circ} \mathrm{N}, 12-9^{\circ} \mathrm{W}$ & 35.45 & 2.68 & 98 \\
\hline & NAC & $16^{\circ} \mathrm{W}, 54-57^{\circ} \mathrm{N}$ & 35.27 & 7.83 & 283 \\
\hline & NRO & $59^{\circ} \mathrm{N}, 13-5^{\circ} \mathrm{W}$ & 35.30 & 9.86 & 357 \\
\hline
\end{tabular}


plays an important role in determining the transports through the Trough, that is equivalent to that of the NAC. We also note that the mean SEC salinity is 35.50 , whereas that of the NAC is fresher, at 35.31. These compare with an output salinity to the Nordic Seas of 35.35, which is intermediate between the two input salinities. With the expectation that salinities in poleward flows through the Rockall Trough will be reduced as they flow northwards as a result of mixing with the less saline ambient water masses, we note that the output salinity is nonetheless higher than that of the NAC input, so it is clear that the SEC is playing a key role in determining such high salinities in the output.

For LEVEL, the volume and salinity transports in the SEC input are about $25 \%$ of those in the NAC input (contributing 1.6 and $6.3 \mathrm{~Sv}$, and 58 and $228 \mathrm{kT} \mathrm{s}^{-1}$ respectively). The sum of these two inputs is approximately equal to the NRO outputs $\left(8.1 \mathrm{~Sv}\right.$ and $\left.295 \mathrm{kT} \mathrm{s}^{-1}\right)$, in contrast to the situation for ISOPYCNIC, in which the sum of the two inputs somewhat exceeds the output. However, the mean salinity of the SEC for LEVEL (35.56) again significantly exceeds that in the NAC input (35.43), so that the influence of the SEC in setting the high salinity in the NRO (35.44) is once again apparent. For SIGMA2, the volume and salinity transports in the SEC input are about $35 \%$ of those in the NAC input (contributing 2.7 and $7.8 \mathrm{~Sv}$, and 98 and $283 \mathrm{kT} \mathrm{s}^{-1}$ respectively), and the sum of these two inputs only slightly exceeds the transports in the output (9.9 Sv and $357 \mathrm{kT} \mathrm{s}^{-1}$ ). Again, the SEC salinity (35.45) is high relative to that in the NAC (35.27), and so its influence in setting the salinity of the NRO output (35.30) at $59^{\circ} \mathrm{N}$ is again clear.

Overall, then, the SEC carries an important input into the Rockall Trough. The volume and salinity transports in the SEC at $50^{\circ} \mathrm{N}$ range between 25 and $100 \%$ of those impacting from the west through $16^{\circ} \mathrm{W}$ in the NAC. We also see that these SEC input transports are a similarly significant proportion (20-75\%) of those output to the Nordic Seas. Moreover, it is clear that the SEC carries the highest salinities into the southern Trough, and so is responsible for setting the high salinity in the flows into the Nordic Seas. This is reinforced by remarking that the SECNAC input salinity differences (at the defined locations) are considerable, amounting to $0.19,0.13$ and 0.18 for ISOPYCNIC, LEVEL and SIGMA2 respectively.

We have here presented the situation for the winter mean case, as this is the time of year which is most critical for determining the mixed layer properties (salinity, density, and thickness) which ventilate the ocean interior (and also to compare with our previous figures). However, we note that the annual mean transports are not much different. Volume transports in the annual mean differ from those presented for the winter mean by typically $0.1-0.2 \mathrm{~Sv}$, salinity transports by approximately $5 \mathrm{kT} \mathrm{s}^{-1}$, and average salinities by $0.01-0.02$. Thus the winter mean case is reasonably representative of the annual mean, and, for instance, it is seen that the currents at the measured locations exhibit very little variability through the annual cycle. The continuity of the SEC from $50^{\circ} \mathrm{N}$ northwards through the Rockall Trough seems adequately demonstrated for the winter case by reference to Figs. 6-8, and also by inference for the other seasons if we keep this remark in mind. (This is borne out by a more detailed investigation of the models.)

Holliday et al. (2000) estimate that the northward salinity transports through the Rockall Trough at $57.5^{\circ} \mathrm{N}$ ranged between between $50-250 \mathrm{kT} \mathrm{s}^{-1}$, during $1975-1998$, with a mean of about 130 $\mathrm{kT} \mathrm{s}^{-1}$. Adding the volume transport estimates (above $500 \mathrm{~m}$ ) of Huthnance (1986) for the SEC, and of Ellett et al. (1986) for the flow in the central Trough, gives a total observed transport near $58^{\circ} \mathrm{N}$ of $4.2 \mathrm{~Sv}$. Thus, the volume and salinity transports derived from ISOPYCNIC seem most reliable at $59^{\circ} \mathrm{N}$ (albeit slightly high), whereas those derived from the other two models are 
approximately double the mean observational estimates, though still at the same order of magnitude, and perhaps (almost) within the variability in Nature.

Turning now to wider issues, it is potentially important in the context of understanding climate variability to elucidate the pathways along which the saline water masses move northwards into the Nordic Seas. If this is via the SEC/NAC, then variability in the deep convection of the Nordic Seas (and Atlantic thermohaline overturning) might result from, and correlate on a relatively short timescale (possibly less than a year) with, variability in the local surface fluxes around the European margins. These local fluxes will act to modify the temperature, salinity, and density of the near-surface waters flowing into the Nordic Seas, and hence their role in either inhibiting or initiating deep mixing. If, however, the saline input is via the deeper MOW route, then variability in the Nordic Seas would be more likely to correlate with variability in the surface fluxes in the Mediterranean Sea on a much longer timescale (probably several decades). Hence a knowledge of which of these routes is operative will aid our understanding of the variability of the Nordic Seas, of the thermohaline overturning of the Atlantic, and of the role these processes might play in climate change.

Recently there has been renewed discussion on the role of the MOW in determining the Atlantic overturning circulation and its effect upon climate. Johnson $(1997,1998)$ has used the basic premise that MOW upwells in the northeast Atlantic (between Scotland and Iceland, i.e. the 'Reid hypothesis') to propose that any increase in the outflow of MOW (which would result from the building of the Aswan Dam) will lead to increased upwelling in this area, diversion of the NAC waters further westwards, and warming of the Labrador Sea. These impacts would in turn lead to enhanced evaporation in the Labrador Sea, an increased snowfall over Canada and a build up of a new ice sheet, and so bring about the onset of a new Ice Age. Rahmstorf (1998) countered Johnson's argument with results from a coupled ocean-atmosphere model in which the likely increased outflow of MOW was tested and had very little effect on the model solution. However, Johnson (1998) suggested that Rahmstorf's model lacked the 'high resolution needed to reveal the critical fine structure of oceanic circulation'. This is true of all present-day coupled models run for climate purposes, in that their ocean components typically have a horizontal resolution of no better than $100 \mathrm{~km}$ or so. However, the models described here have much higher resolution (20 km in the Rockall Trough region) and can resolve the details of the flow fields reasonably well. As we have seen, they agree that MOW does not upwell as envisaged by Reid, which is counter to Johnson's hypothesis, and in support of Rahmstorf's conclusion.

In summary, we feel the present study has provided valuable insights into the circulation patterns of the North Atlantic near the European margins. A particular strength has been the investigation of three independent models: the similarities and differences between the models has allowed conclusions to be drawn which are more robust than those which would have resulted from a single model alone. The models agree that Mediterranean Overflow Water does not upwell and provide the saline inflows to the Nordic Seas. Instead, they all indicate that these inflows are derived partially from branches of the North Atlantic Current, and partially from the Shelf Edge Current (SEC), both of which are upper-ocean flows. Furthermore, the highest salinities are typically set in the Bay of Biscay region, which is the formation area for the saline Eastern North Atlantic Water, and transported polewards by the SEC. To our knowledge, this is the first time that the SEC has been proposed as playing a major role in this respect. The models show reasonable agreement with inferences drawn from the available observational data, and have illustrated 
the complexity of the likely flows in this area. This complexity is of potential interest to the offshore industries producing oil, gas, and maybe in the future more renewable energy, the fishing industry, and for navigation. The study has also contributed to an ongoing community effort to assess the realism of our current generation of ocean circulation models.

\section{Acknowledgements}

The work reported in this paper is part of the 'DYNAMO' project which has been supported by the European Union Marine Science and Technology programme under contract no. MAS2CT93-0060. This support is gratefully acknowledged. We would like to thank our colleagues B. Barnier, A. Beckmann, C. W. Böning, M. Coulibaly, D. de Cuevas, J. Dengg, C. Dieterich, Y. Jia, P. D. Killworth, M.-M. Lee, C. Le Provost, A. Oschlies, R. Redler, T. Reynaud, A. Schiller, L. J. West and J. Willebrand, who contributed to various stages of the project. We also acknowledge the provision of supercomputing facilities by the Rechenzentrum der Universität Kiel, the Deutsches Klimarechenzentrum Hamburg, the Atlas Centre at the Rutherford Appleton Laboratory, and the Institut pour le Développement des Ressources en Informatique Scientifique, Centre National de la Recherche Scientifique. Finally, we would like to thank anonymous reviewers for helpful comments on an early draft of the manuscript.

\section{References}

Bersch, M. (1995). On the circulation of the northeastern North Atlantic. Deep-Sea Research, 42, 1583-1607.

Bleck, R., Rooth, C., Hu, D., \& Smith, L. T. (1992). Salinity-driven thermocline transients in a wind- and thermohalineforced isopycnic coordinate model of the North Atlantic. Journal of Physical Oceanography, 22, 1486-1505.

Cox, M. D. (1984). A primitive equation, 3-dimensional model of the ocean. In Technical Report 1. Princeton, NJ, USA: Ocean Group, Geophysical Fluid Dynamics Laboratory, 143 pp.

Daniault, N., Mazé, J. P., \& Arhan, M. (1994). Circulation and mixing of Mediterranean Water west of the Iberian Peninsula. Deep-Sea Research, 41, 1685-1714.

Dickson, R. R., \& Brown, J. (1994). The production of North Atlantic Deep Water: sources, rates and pathways. Journal of Geophysical Research, 99, 12319-12341.

DYNAMO Group (Barnard, S., Barnier, B., Beckmann, A., Böning, C. W., Coulibaly, M., de Cuevas, D., Dengg, J., Dieterich, C., Ernst, U., Herrmann, P., Jia, Y., Killworth, P. D., Kröger, J., Lee, M.-M., Le Provost, C., Molines, J.-M., New, A. L., Oschlies, A., Reynaud, T., West, L. J., and Willebrand, J.) (1997). DYNAMO: dynamics of North Atlantic Models: simulation and assimilation with high resolution models. Berichte aus dem Institut für Meereskunde an der Christian-Albrechts-Universität Kiel, 294, 334 pp.

Ellett, D. J., Edwards, A., \& Bowers, R. (1986). The hydrography of the Rockall Channel — an overview. Proceedings of the Royal Society of Edinburgh, 88B, 61-81.

Haidvogel, D. B., Wilkin, J. L., \& Young, R. (1991). A semi-spectral primitive equation ocean circulation model using vertical SIGMA2 and orthogonal curvilinear horizontal coordinates. Journal of Computational Physics, 94, 151-185.

Haynes, R., \& Barton, E. D. (1990). A poleward flow along the Atlantic coast of the Iberian peninsula. Journal of Geophysical Research, 95, 11425-11441.

Hill, A. E., \& Mitchelson-Jacob, E. G. (1993). Observations of a poleward-flowing saline core on the continental slope west of Scotland. Deep-Sea Research, 40, 1521-1527.

Holliday, N. P., Pollard, R. T., Read, J. F., \& Leach, H. (2000). Water mass properties and fluxes in the Rockall Trough: 1975 to 1998. Deep-Sea Research I, 47, 1303-1332. 
Holloway, G. (1992). Representing topographic stress for large-scale ocean models. Journal of Physical Oceanography, 22, 1033-1046.

Huthnance, J. M. (1984). Slope currents and 'JEBAR'. Journal of Physical Oceanography, 14, 795-810.

Huthnance, J. M. (1986). The Rockall slope current and shelf edge processes. Proceedings of the Royal Society of Edinburgh, 88B, 83-101.

Huthnance, J. M. (1987). Along-shelf evolution and sea levels across the continental slope. Continental Shelf Research, 7, 957-974.

Huthnance, J. M., Mysak, L. A., \& Wang, D.-P. (1986). Coastal trapped waves. In Baroclinic Processes on Continental Shelves, Coastal and Estuarine Sciences, 3, 1-18.

Johnson, R. G. (1997). Climate control requires a dam at the Strait of Gibraltar. EOS, Transactions, American Geophysical Union, 78, 277-280.

Johnson, R. G. (1998). Comment on Rahmstorf's 1998 article. EOS, Transactions, American Geophysical Union, 79 , 292.

Killworth, P. D. (1996). Time interpolation of forcing fields in ocean models. Journal of Physical Oceanography, 26, 136-143.

Levitus, S. (1982). Climatological atlas of the world ocean. NOAA Professional Paper 13, US Department of Commerce, National Oceanic and Atmospheric Administration, 173 pp.

Lozier, M. S., Owens, W. B., \& Curry, R. G. (1995). The climatology of the North Atlantic. Progress in Oceanography, $36,1-44$.

McCartney, M. S., \& Mauritzen, C. (2001). On the origin of the warm inflow to the Nordic Seas. Progress in Oceanography (in press)

Pingree, R. D. (1993). Flow of surface waters to the west of the British Isles and in the Bay of Biscay. Deep-Sea Research, 40, 369-388.

Pingree, R. D., \& Le Cann, B. (1989). Celtic and Armorican slope and shelf residual currents. Progress in Oceanography, 23, 303-338.

Pingree, R. D., \& Le Cann, B. (1990). Structure, strength and seasonality of the slope currents in the Bay of Biscay region. Journal of the Marine Biological Association of the U.K., 70, 857-885.

Pingree, R. D., Sinha, B., \& Griffiths, C. R. (1999). Seasonality of the European slope current (Goban Spur) and ocean margin exchange. Continental Shelf Research, 19, 929-975.

Pollard, R. T., Griffiths, M. J., Cunningham, S. A., Read, J. F., Pérez, F. F., \& Ríos, A. F. (1996). Vivaldi 1991 A study of the formation, circulation and ventilation of Eastern North Atlantic Central Water. Progress in Oceanography, 37, 167-192.

Rahmstorf, S. (1998). Influence of Mediterranean outflow on climate. EOS, Transactions, American Geophysical Union, 79, 281-282.

Reid, J. L. (1979). On the contribution of the Mediterranean Sea outflow to the Norwegian-Greenland Sea. Deep-Sea Research, 26, 1199-1223.

White, M., \& Bowyer, P. (1997). The shelf-edge current north-west of Ireland. Annales Geophysicae, 15, $1076-1083$.

Willebrand, J., Barnier, B., Böning, C. W., Dieterich, C., Herrmann, P., Killworth, P. D., Le Provost, C., Jia, Y., Molines, J.-M., \& New, A. L. (2001). Circulation characteristics in three eddy-permitting models of the North Atlantic. Progress in Oceanography, 48, 000-000 this issue.

Zenk, W., \& Armi, L. (1990). The complex spreading pattern of Mediterranean Water off the Portuguese continental slope. Deep-Sea Research, 37, 1805-1823. 